\title{
Interactions Between Ticks and Lyme Disease Spirochetes
}

\author{
Utpal Pal ${ }^{1,2 *}$, Chrysoula Kitsou ${ }^{1}$, Dan Drecktrah ${ }^{3}$, Özlem Büyüktanir Yaş ${ }^{4}$ and Erol Fikrig ${ }^{5}$ \\ 1Department of Veterinary Medicine, University of Maryland, 8075 Greenmead Drive, College Park, MD 20742, USA \\ 2Virginia-Maryland College of Veterinary Medicine, 8075 Greenmead Drive, College Park, MD 20742, USA \\ ${ }^{3}$ Division of Biological Sciences, University of Montana, Missoula, MT, 59812, USA \\ ${ }^{4}$ Department of Microbiology and Clinical Microbiology, Faculty of Medicine, Istinye University, Zeytinburnu, İstanbul, \\ 34010, Turkey \\ ${ }^{5}$ Section of Infectious Diseases, Department of Internal Medicine, Yale University School of Medicine, New Haven, CT \\ 06520, USA \\ *Corresponding author: upal@umd.edu
}

DOI: https://doi.org/10.21775/cimb.042.113

\begin{abstract}
Borrelia burgdorferi sensu lato causes Lyme borreliosis in a variety of animals and humans. These atypical bacterial pathogens are maintained in a complex enzootic life cycle that primarily involves a vertebrate host and Ixodes spp. ticks. In the Northeastern United States, I. scapularis is the main vector, while wild rodents serve as the mammalian reservoir host. As $B$. burgdorferi is transmitted only by $I$. scapularis and closely related ticks, the spirochete-tick interactions are thought to be highly specific. Various borrelial and arthropod proteins that directly or indirectly contribute to the natural cycle of $B$. burgdorferi infection have been identified. Discrete molecular interactions between spirochetes and tick components also have been discovered, which often play critical roles in pathogen persistence and transmission by the arthropod vector. This review will focus on the past discoveries and future challenges that are relevant to our understanding of the molecular interactions between $B$. burgdorferi and Ixodes ticks. This information will not only impact scientific advancements in the research of ticktransmitted infections but will also contribute to the development of novel preventive measures that interfere with the $B$. burgdorferi life cycle.
\end{abstract}

\section{Introduction}

Ixodes ticks transmit a wide range of infections, including Lyme disease, to animals and humans (Nadelman and Wormser, 1998; Radolf et al., 2012; Nelder et al., 2016; Steere et al., 2016; Stanek and Strle, 2018). Lyme disease is a prominent tick-borne illness (Benach et al., 1983) that features widespread distribution (Mead, 2015) and is caused by a group of spirochetes belonging to the Borrelia burgdorferi sensu lato complex (Burgdorfer et al., 1988). Recently, more virulent (albeit less prevalent) strains of Borrelia pathogens have been identified, including new clinical isolates of $B$. burgdorferi sensu lato, $B$. bissettii, B. mayonii, and B. miyamotoi, which are also transmitted by Ixodes ticks and are associated with severe human diseases (Krause et al., 2015; Pritt et al., 2016; Radolf and Samuels, 2021; Rudenko et al., 2016). Globally, the Borrelia species that are commonly associated with Lyme disease include $B$. burgdorferi sensu stricto, which is prevalent throughout the United States and Europe, and $B$. afzelii and $B$. garinii, which are distributed throughout Eurasia (Nadelman and Wormser, 1998; Piesman and Gern, 2004; Mead, 2015).

In North America and Europe, Lyme disease spirochetes typically are maintained in nature through a complex tick-rodent infection cycle. Larval ticks acquire the pathogen while feeding on infected wild hosts, such as white-footed mice (Anderson et al., 1987; Anderson, 1989), and then transstadially maintain $B$. burgdorferi before transmitting the pathogen back to a naïve host during the subsequent blood meal (Steere, 2001; Steere et al., 2004). Humans and domesticated animals that develop Lyme disease are incidental hosts and do not play a role in the natural transmission cycle (Radolf et al., 2012).

B. burgdorferi does not readily infect most tick species, suggesting that its interactions with $I$. 
scapularis are highly specific. Limited studies have shed light on these complex pathogen-tick interactions (Munderloh and Kurtti, 1995; Fikrig and Narasimhan, 2006); a recent review summarizes our most current state of knowledge about the interactions between $B$. burgdorferi and I. scapularis ticks (Kurokawa et al., 2020). Vector competence, which depends on genetic determinants influencing the vector's ability to transmit a pathogen, also shapes interactions involving the tick, pathogen, and host (de la Fuente et al., 2017). With the advent of genetic tools for creating Borrelia mutants (Samuels et al., 2018) (see also Radolf and Samuels, 2021) and the current availability of the $I$. scapularis genome (Gulia-Nuss et al., 2016; Miller et al., 2018), investigators will have increasingly robust tools for studying Borrelia-tick interactions, both during the arthropod phase of the spirochete life cycle and at the interface with the mammalian host. A few borrelial proteins already have been demonstrated as prerequisites for spirochete-vector interactions, particularly with receptors in select tick organs, such as the gut or salivary gland (Ramamoorthi et al., 2005; Rosa, 2005; Dunham-Ems et al., 2009; Zhang et al., 2011; Radolf et al., 2012). The adaptation of Borrelia to the vector or host also requires the tightlycontrolled regulation of bacterial gene expression (Hubner et al., 2001; Caimano et al., 2005; Fisher et al., 2005; Caimano et al., 2007; Samuels, 2011; Caimano et al., 2016; Stevenson and Seshu, 2018). Exciting new studies have elucidated the complexities of gene regulation by $B$. burgdorferi in ticks (Radolf and Samuels, 2021). The RpoN/RpoS pathway is active in feeding nymphs (Caimano et al., 2007) and induces a set of proteins that are mandatory for $B$. burgdorferi transmission from ticks, as well as for host infection (Fisher et al., 2005). Additional proteins and nucleotide factors, like Rel Bbu $_{\text {B }}$ or 5'-triphosphate-guanosine-3'-diphosphate and 5'diphosphate-guanosine-3'-diphosphate (collectively known as (p)ppGpp), are required for borrelial persistence, while the Hk1/Rrp1 two-component system and c-di-GMP are required for host transitions and the evasion of tick defenses (Bugrysheva et al., 2015; Caimano et al., 2015; Caimano et al., 2016). More recently, a large number of small noncoding RNAs (sRNAs) were discovered to be encoded in the borrelial genome, some of which are regulators of gene expression (Drecktrah et al., 2018). Future studies of Borrelia-tick interactions will allow us to understand the unique adaptive strategies of the bacterium for its survival in an extremely diverse range of host tissues. This information will contribute to the development of novel preventive measures against borrelial infection. The following sections will review how the molecular interactions of select $B$. burgdorferi and $I$. scapularis gene products support the pathogen's life cycle in nature. We also will comment on recent advances in Ixodes genomics, as well as other "omics" technologies (Hasin et al., 2017), and discuss how tick interaction studies may contribute to the development of a transmission-blocking Lyme disease vaccine.

\section{The $B$. burgdorferi life cycle in ticks}

$B$. burgdorferi survives in nature in a tick-mammal infection cycle (Anguita et al., 2003; Pal and Fikrig, 2003; Caimano et al., 2016). Given the lack of transovarial transmission, the pathogen needs to be acquired during one of the life stages of its vector at the time of engorgement on infected mammals, primarily wild rodents (Anderson, 1989; Munderloh and Kurtti, 1995; Pal and Fikrig, 2003). As the arthropod prepares for its blood meal ingestion within the first 12 hours of tick attachment to the host, the transfer of spirochetes to the vector already has begun. The details remain uncertain as to how $B$. burgdorferi transmits between the arthropod and vertebrate host, either by the active chemotactic migration of spirochetes or via passive transfer along with host fluid. During acquisition, spirochetes enter the tick gut from the dermis of an infected host and presumably continue to migrate until the tick is fully engorged, which usually takes $72-96$ hours (Piesman et al., 1990; de Silva and Fikrig, 1995). B. burgdorferi intimately associates with the midgut tissues within 48 hours of feeding (Yang et al., 2004), and can persist in the gut throughout the life span of the arthropod (Pal et al., 2001). When the tick ingests a subsequent blood meal, the spirochetes multiply in the gut; at this time, an unknown fraction of the $B$. burgdorferi population exits the gut, enters the hemocoel, disseminates towards the salivary glands, and is transmitted through the salivary stream to the new mammalian host (de Silva and Fikrig, 1995; Coleman et al., 1997; Piesman et al., 2001; Schwan and Piesman, 2002; Dunham-Ems et al., 2009). The following section will highlight the varied environments and formidable challenges that $B$. burgdorferi encounters during its entry, long-term persistence, and subsequent transmission through ticks. 
B. burgdorferi encounters diverse tick environments The feeding gut during acquisition

When acquired from mammals, $B$. burgdorferi adapts to an entirely new environment in the vector. Despite recent breakthroughs (Smith and Pal, 2014; Smith et al., 2016; Oliva Chavez et al., 2017; Shaw et al., 2017; Shaw et al., 2018), relatively little is known about the immune system of the tick. Nevertheless, the feeding tick gut can be presumed to present a hostile environment, which $B$. burgdorferi encounters immediately following acquisition (Smith et al., 2016) (see also Radolf and Samuels, 2021). As spirochetes migrate into the luminal spaces of the gut and colonize it, they must avoid being digested with the blood meal and also must bypass the tick's innate immune defense mechanisms (Hynes et al., 2005). Phagocytosis allows the tick gut cells to capture constituents of the blood meal, such as cellular remnants and hemoglobin crystals (Sonenshine, 1993), although the ingestion of $B$. burgdorferi is

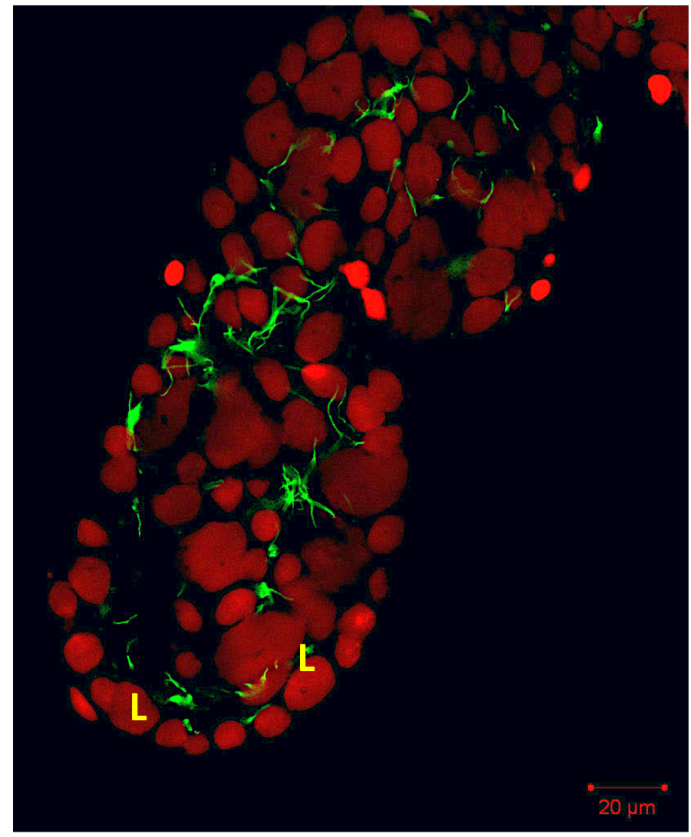

Figure 1. Colonized B. burgdorferi within the gut diverticulum of a nymphal $I$. scapularis. The gut of an unfed nymphal $I$. scapularis tick was dissected and processed for confocal immunofluorescence microscopy, as detailed (Pal et al., 2004a). The image shows a portion of the gut diverticulum, where tick nuclei (red) were labeled with propidium iodide, and spirochetes towards the luminal side (green) were detected using FITC-labeled anti-B. burgdorferi antibodies. L, Lumen of the gut, $\mathrm{Bar}=20 \mu \mathrm{m}$. rarely observed. While gastric digestion in ticks is primarily intracellular (Sonenshine, 1993), with intraluminal proteases virtually absent, the degradation of blood meal components could lead to peptides that have antimicrobial activities (Fogaca et al., 1999; Nakajima et al., 2003). In addition, ticks also may produce conventional antimicrobial peptides in the gut (Broadwater et al., 2002; Hynes et al., 2005). An I. ricinus defensin-like gene is upregulated in the gut after infection with $B$. burgdorferi (Grubhoffer et al., 2005); however, the mechanism by which the spirochetes evade this innate immune defense is unknown. Ixodes ticks also form a transient acellular peritrophic membrane (PM) that surrounds the blood meal (elaborated upon below). It remains unclear as to how this barrier influences $B$. burgdorferi acquisition and colonization of the gut epithelium in ticks. Invading spirochetes could rapidly colonize the gut epithelial cells prior to the formation of a peritrophic barrier or, alternatively, spirochetes could cross the peritrophic membrane after its formation and colonize the underlying gut epithelium. In either case, the peritrophic barrier could protect the bacteria that are bound to the midgut epithelium against the toxic contents of the lumen.

The unfed gut

In its natural cycle, B. burgdorferi persists in its arthropod vectors for months, confined to the guts of unfed ticks. Ixodes have a relatively long life cycle spanning at least 18 months (Ullmann et al., 2005), a significant part of which is dominated by phases of nutrient deprivation and limited metabolic activity (Sonenshine, 1993). Little is known about the mechanisms by which $B$. burgdorferi persists in unfed ticks (Figure 1), although more recent studies have suggested that the alteration of metabolic pathways may play a critical role in spirochete persistence. For example, studies have shown that the Hk1/Rrp1/c-di-

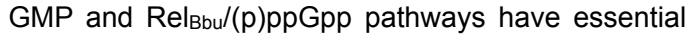
functions in spirochete adaptation and survival, include a necessary shift in carbon utilization from glucose to glycerol (He et al., 2011; Pappas et al., 2011; Drecktrah et al., 2015; Caimano et al., 2016). Residing within the gut of the poikilotherm, spirochetes also must survive the extremes of seasonal changes, as well as daily temperature fluctuations in temperate climates. The lumen of the unfed gut (Figure 1) is poor in residual nutrients, primarily because gut epithelia store nutrient macromolecules within cellular endosomes, leaving the lumen devoid of nutrients (Sonenshine, 1993). 
Genes expressed by $B$. burgdorferi in the unfed gut, or in "tick-like" growth conditions in vitro, could be associated with the maintenance of the most elemental functions for persistence in the nutrientdepleted and anoxic environment of the arthropod (Ojaimi et al., 2002; Revel et al., 2002). Spirochetes are known to upregulate specific gene products that protect DNA against starvation or oxidative stressinduced damage during the long intermolt period between blood meals (described below). Alternate forms of $B$. burgdorferi, called round bodies (RBs), also have been reported, especially under unfavorable conditions in vitro (Brorson and Brorson, 1998; Alban et al., 2000; Brorson and Brorson, 2004; Drecktrah et al., 2015), in ticks in vivo (Dunham-Ems et al., 2012), and in incidental hosts in vivo (Brorson and Brorson, 1998; Duray et al., 2005).

\section{Feeding gut during transmission}

Tick attachment to a host initiates a remarkable series of metabolic changes in the gut (Sonenshine, 1993). During the first 36 hours of host attachment, blood enters the tick slowly, and there is little digestive activity (Sauer, 1986; Sonenshine, 1993). Spirochetes in the gut must sense the appropriate physiochemical stimuli before they begin multiplying. Following 24 hours of host attachment, $B$. burgdorferi is principally confined within the lumen of the tick gut; by 72 hours, it is dispersed throughout the entire gut tissue (Pal and Fikrig, 2003). Although the density of $B$. burgdorferi in the gut increases exponentially as feeding progresses (Piesman et al., 1990; de Silva and Fikrig, 1995), thereby generating a phenotypically diverse population of spirochetes (Ohnishi et al., 2001; Srivastava and de Silva, 2008), the majority of the bacteria do not exit the gut. Only a fraction of spirochetes cross the gut epithelial barrier and disseminate to the hemocoel for transmission to the host via the salivary gland (Coleman et al., 1997). A seminal study provided a detailed mechanistic view of how $B$. burgdorferi travels through the feeding gut during transmission from infected ticks, using an unprecedented biphasic mode of dissemination (Dunham-Ems et al., 2009). In the initial phase of dissemination, the replicating spirochetes in the midgut form networks of nonmotile organisms, which later advance toward the basolateral gut surface via adherence to the resident gut epithelial cells. In the subsequent phase, the spirochetes become motile, invade the gut basement membrane, and migrate to the salivary glands through the hemocoel (DunhamEms et al., 2009). Future studies are warranted to decipher the identities of the tick and microbial components, or additional mechanisms that influence $B$. burgdorferi dissemination from the gut. Hostderived plasminogen has been implicated in the efficient dissemination of Borrelia within the tick, and in the enhancement of spirochetemia in vertebrate hosts (Coleman et al., 1995; Coleman et al., 1997). As previously mentioned, an ephemeral and porous peritrophic membrane (PM) is formed in the infected tick gut during feeding, which engulfs the blood meal and $B$. burgdorferi in the lumen (Rudzinska et al., 1982; Sonenshine, 1993), and is clearly visible within 36 hours of the onset of feeding. This membrane is a mechanical barrier, and particulate matters from the ingested blood meal can be retained in the lumen proper (Rudzinska et al., 1982). B. burgdorferi can be detected in the lumen of the feeding gut (Pal and Fikrig, 2003; Dunham-Ems et al., 2009); however, it is unknown as to how the physical division of the gut luminal spaces and epithelial tissues, as imposed by the peritrophic membrane, influences spirochete transmission. The integrity of the peritrophic membrane, which is essential for $B$. burgdorferi to efficiently colonize the gut epithelium, is influenced by extrinsic factors, such as the gut microbiota, or intrinsic proteins, like the transcription factor STAT (Kariu et al., 2013; Narasimhan et al., 2014b). Although studies have yet to define precisely how $B$. burgdorferi penetrates through the PM, another tickborne pathogen, Babesia microti, is reported to develop a highly specialized organelle, the arrowhead, which helps the microbe to cross the peritrophic barrier of Ixodes ticks (Rudzinska et al., 1982). Nevertheless, the peritrophic membrane and its constituents have been shown to influence pathogen persistence or dissemination in many other arthropod-borne pathogens, including B. burgdorferi (Pimenta et al., 1997; Beerntsen et al., 2000; Kariu et al., 2013).

\section{The hemocoel}

During transmission, $B$. burgdorferi needs to traverse the hemocoel to access the salivary glands. In arthropods, the cellular constituents of the hemocoel are dominated by actively phagocytic blood cells or hemocytes that are the primary mediators of the arthropod innate immune responses (Sauer, 1986; Sonenshine, 1993). Little is known about how $B$. burgdorferi travels through the tick hemolymph, avoids phagocytosis and the innate immune defense of hemocytes, and selectively recognizes and enters the salivary gland. Studies indicate that a significant percentage $(13 \pm 5 \%)$ of isolated hemocytes in feeding $l$. scapularis could be associated with 
disseminated spirochetes (Coleman et al., 1997), although the biological significance of the Ixodes hemocyte-spirochete association is not clear. In another study, when $B$. burgdorferi was experimentally injected into the hemocoels of $I$. scapularis and Dermacentor variabilis, a noncompetent tick vector of Borrelia, the spirochetes readily survived in the Ixodes hemolymph, whereas they were rapidly killed by hemocytes in the $D$. variabilis hemolymph, suggesting that $B$. burgdorferi is resistant to killing by Ixodes hemocytes (Johns et al., 2001). The recent availability of the $I$. ricinus hemocytome, as analyzed by next-generation sequencing technologies (Kotsyfakis et al., 2015), will contribute to our understanding of Ixodes hemocyte biology, including its role in spirochete interactions (Kurokawa et al., 2020). While the number of $B$. burgdorferi in the infected tick gut increases exponentially (Piesman et al., 1990; Piesman et al., 2001), the exact proportion of spirochetes that cross the gut epithelial barrier and systemically disseminate to the salivary gland through the hemocoel is unknown. Studies of infected $I$. scapularis during feeding indicate that approximately $5 \%$ and $0.7 \%$ of the gut spirochetes can be detected in the hemolymph and salivary glands, respectively (Coleman et al., 1997). Future studies on the kinetics and mechanisms of $B$. burgdorferi dissemination through the Ixodes hemocoel should provide important insights into the development of novel inhibitory measures against spirochete transmission from ticks to mammals.

The salivary gland

The salivary gland represents the other major tick organ (Sauer, 1986; Sonenshine, 1993) that spirochetes must traverse during transmission to a mammalian host. The saliva from an engorging tick, which is deposited in the tick bite site of the host dermis, plays a pivotal role in pathogen transmission (Simo et al., 2017; Nuttall, 2019). Once B. burgdorferi is acquired by the tick vector from an infected host, the pathogen resides in the tick gut and does not infect the salivary glands (Piesman, 1993; Piesman et al., 2001; Pal and Fikrig, 2003; Fikrig and Narasimhan, 2006). The spirochetes migrate from the infected tick gut to the salivary glands during a subsequent blood meal, which lasts for 3-7 days (Piesman, 1993; Piesman et al., 2001; Pal and Fikrig, 2003; Fikrig and Narasimhan, 2006). In comparison, $B$. hermsii, the relapsing fever spirochetes, readily colonize the salivary glands of unfed soft ticks, Ornithodoros hermsi (Sonenshine, 1993; Schwan and Piesman, 2002); soft ticks are fast feeders, and these particular spirochetes are transmitted within seconds of vector attachment to a mammalian host (Schwan and Piesman, 2002; Boyle et al., 2014). Regardless of the kinetics of transmission, tick salivary glands potentially act as the second distinct barrier that most arthropod-borne pathogens must cross for efficient transmission. Other tick-borne bacterial diseases, such as Anaplasma marginale, require active replication within the salivary gland for effective transmission (Ueti et al., 2007), yet there is no evidence of a similar event for $B$. burgdorferi within the tick. Borrelial spirochetes invade the salivary gland by an undefined mechanism, after which they may be passively carried to the host dermis, along with tick saliva. As several salivary gland genes are upregulated in infected $I$. scapularis nymphs, in comparison to uninfected nymphs (Ribeiro et al., 2006), salivary gland proteins may play an important role in $B$. burgdorferi transmission and infection.

\section{Regulation of gene expression in ticks}

$B$. burgdorferi alters its gene expression profile as it cycles between arthropods and mammals (de Silva and Fikrig, 1997; Anguita et al., 2003; Schwan, 2003; Rosa et al., 2005; Stevenson and Seshu, 2018), and specific genes maintain the spirochete infection cycle in nature (Coburn and Cugini, 2003; Purser et al., 2003; Grimm et al., 2004b; Pal et al., 2004b; Yang et al., 2004; Revel et al., 2005; Rosa et al., 2005; Li et al., 2007b; Pal et al., 2008b). Gene regulation in $B$. burgdorferi is the subject of several reviews, such as (Samuels, 2011; Caimano et al., 2016; Stevenson and Seshu, 2018) (see also Radolf and Samuels, 2021). The diverse microenvironments within vector tissues likely induce the changes in pathogen gene expression that are required for survival. In contrast to many pathogenic bacteria, B. burgdorferi devotes large portions of its genome (more than $8 \%$ of its coding genes) toward the production of approximately 150 lipoproteins (Fraser et al., 1997; Casjens et al., 2000; Schutzer et al., 2011), many of which are predicted to be exposed on the bacterial surface and be differentially expressed. A number of studies have attempted to identify $B$. burgdorferi genes that are selectively upregulated in the environments of either unfed or fed ticks in vivo (Narasimhan et al., 2002; Kumar et al., 2011; Dunham-Ems et al., 2012; lyer et al., 2015; Groshong et al., 2017). The comparative microarray study revealed wide-spread global changes in expression of genes encoding lipoproteins, carbon 
utilization, nutrient uptake, intermediate metabolism and chemotaxis when comparing the transcriptomes of fed larvae and fed nymphs, as well as to those of $B$. burgdorferi cultured in vitro and in dialysis membrane chambers in the host (lyer et al., 2015). This all-encompassing view of the transcriptomic modulation in the spirochetes grown in culture or in the vector provides an appreciable picture of the actual changes in the in vivo model of Lyme disease, while dissecting individual mechanisms regulating expression have mostly relied on specific in vitro conditions. To that end, a number of microarray and RNA-seq studies have provided indirect but important clues about the regulation and function of $B$. burgdorferi genes in in vitro culture models, in some cases partly mimicking tick-specific environments (Narasimhan et al., 2002; Ojaimi et al., 2002; Revel et al., 2002; Brooks et al., 2003; Ojaimi et al., 2003; Tokarz et al., 2004; Fisher et al., 2005; Bugrysheva et al., 2015; Caimano et al., 2015; Drecktrah et al., 2015; Arnold et al., 2016; Arnold et al., 2018; Boyle et al., 2019; Caimano et al., 2019). Temperature changes used to mimic the tick environment $\left(23^{\circ} \mathrm{C}\right)$ and incoming blood meal during tick feeding and host environment $\left(37^{\circ} \mathrm{C}\right)$ have identified this variable as an important regulator of global gene expression, albeit by unknown mechanisms (Ojaimi et al., 2002). Such studies have important implications, as the temperature in the tick gut changes rapidly during feeding, rising from the ambient arthropod temperature to mammalian body temperature, resulting in the modulation of the expression of genes necessary to establish infection, notably those encoding lipoproteins, especially outer surface lipoprotein C (ospC) (Schwan et al., 1995). Another simulation of the conditions of feeding ticks was accomplished by the addition of blood to spirochete cultures, which also induced major remodeling of the transcriptome with some similarities to temperature shifting, but also significant distinctions (Tokarz et al., 2004).

Induction of the RpoN-RpoS alternative sigma factor pathway, where RpoN controls the expression of RpoS (Hübner et al., 2001), is regarded as a key genetic regulatory network in $B$. burgdorferi, particularly during transmission from ticks to the host. The RpoN-RpoS pathway activates many spirochete genes in feeding ticks, implying a role in $B$. burgdorferi transmission through ticks. Both rpoN null and rpos null mutants successfully colonized tick guts, but were unable to invade salivary glands or infect the vertebrate host (Fisher et al., 2005;
Dunham-Ems et al., 2012). These studies indicate that genes regulated by RpoN and RpoS are involved in transmission from the vector to the host. The expression of the alternative sigma factor, rpos, is selectively induced during the nymphal blood meal, suggesting a potential role of RpoS as an activator of genes that are relevant to spirochete transmission and the establishment of early infection in a mammalian host (Caimano et al., 2004; Caimano et al., 2007; Dunham-Ems et al., 2012; Caimano et al., 2019). Individual spirochete genes also have been identified that show dramatic expression in ticks, such as ospA, ospB, ospC, ospD, ospE, ospF, elp, $b p t A, d p s, \operatorname{csp} A$, and $l a 7$, and that may play important roles in tick tissue colonization, transmission, and infection of a new host (Schwan et al., 1995; Schwan and Piesman, 2000; Ojaimi et al., 2002; Brooks et al., 2003; Grimm et al., 2004b; Tokarz et al., 2004; Yang et al., 2004; Revel et al., 2005; Bykowski et al., 2007a; Bykowski et al., 2007b; Caimano et al., 2007; Li et al., 2007b; Neelakanta et al., 2007; Pal et al., 2008a). Although many of these genes belong to $B$. burgdorferi paralogous gene families, such as Erps (OspE/F-related proteins), individual members have presented distinct expression patterns in the infected tick during feeding and transmission to the mammalian host. For example, whereas $o s p E$, ospF, and $b b k 2.11$ display progressive induction in the gut while the arthropod is being engorged on the blood meal, certain members of the elp family, such as bbk2.10 and ospE/F homolog $p 21$, are expressed only at some later points of feeding and dissemination (Hefty et al., 2001).

The two intracellular second messengers guanosine tetraphosphate and pentaphosphate, collectively known as (p)ppGpp, and cyclic-di-GMP (c-di-GMP) are important signaling molecules that globally alter gene expression to adapt $B$. burgdorferi for persistence in the tick (He et al., 2011; Bugrysheva et al., 2015; Caimano et al., 2015; Drecktrah et al., 2015). The levels of (p)ppGpp are controlled by the

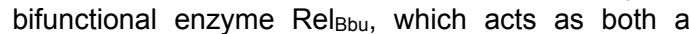
synthetase and hydrolase to regulate the stringent response (Fraser et al., 1997; Concepcion and Nelson, 2003; Bugrysheva et al., 2005; Drecktrah et al., 2015). When $B$. burgdorferi is nutrient stressed in vitro, conditions used to simulate the tick environment between bloodmeals, levels of (p)ppGpp increase, leading to global changes in gene expression and sRNA levels (Bugrysheva et al., 2015; Drecktrah et al., 2015; Drecktrah et al., 2018). 
Genes encoding specific proteins involved in several pathways are targeted for regulation, including carbohydrate metabolism and persistence in the tick, such as the glycerol metabolism $(g / p)$ operon (Bugrysheva et al., 2015; Drecktrah et al., 2015). The

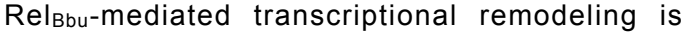
important for persistence in the tick as a null mutant is compromised for survival between bloodmeals (Drecktrah et al., 2015). Additionally, the transcriptional regulator DksA also alters gene expression during nutrient stress both cooperatively and independently of (p)ppGpp, targeting similar functional pathways, such as the glp operon, and distinct ones as well (Boyle et al., 2019). Together, Rel $_{\mathrm{Bbu}}$ and DksA regulate the stringent response to control gene expression to adapt $B$. burgdorferi for persistence in the tick.

A series of studies described the identification and molecular characterization of a c-di-GMP regulatory system, which revealed a critical role in spirochete gene expression, motility, and survival in the tick (Freedman et al., 2010; Pitzer et al., 2011; He et al., 2014; Novak et al., 2014; Mallory et al., 2016; Kostick-Dunn et al., 2018; Zhang et al., 2018). Rrp1, a diguanulate cyclase of the two-component regulatory system Hk1-Rrp1, synthesizes c-di-GMP in response to as of yet unidentified signals to globally modulate gene expression, including those encoding genes involved in carbon utilization, notably, like the stringent response, the glp operon, and surface lipoproteins (Rogers et al., 2009; Sze et al., 2013; Caimano et al., 2015). The rrp1 mutants unable to synthesize c-di-GMP have a dramatic survival defect in feeding larvae and nymphs, indicating that the c-di-GMP-mediated transcriptional changes likely adapt the spirochete for persistence (He et al., 2011; Kostick et al., 2011; Caimano et al., 2015). At least some of the effects of c-di-GMP on transcription may be mediated by the c-di-GMP binding protein PlzA, and in some strains PlzB (Freedman et al., 2010; Pitzer et al., 2011; He et al., 2014; Kostick-Dunn et al., 2018; Zhang et al., 2018). Overexpression of PIzA partially compensates for the survival defect of rrp1 mutants (He et al., 2014).

The remarkable convergence of transcriptional regulatory mechanisms on the glp operon suggests a finely tuned, central role for these gene products in the tick. This operon is regulated during conditions that mimic the tick environment by both Rel Bbu and DksA, Rrp1 and PIzA, as well as RpoS, the DNAbinding protein BadR, temperature and glycerol
(Ojaimi et al., 2003; Caimano et al., 2007; He et al., 2011; Bugrysheva et al., 2015; Caimano et al., 2015; Drecktrah et al., 2015; Arnold et al., 2018; Zhang et al., 2018; Boyle et al., 2019). In fact, mutant strains with compromised glycerol metabolism, likely provided by the bloodmeal or tick itself, show a significant survival defect in ticks (Pappas et al., 2011). The utilization of glycerol within the tick phase of the $B$. burgdorferi life cycle is a prime example of the multiple mechanisms of gene regulation invoked by the spirochete in response to the arthropod environment in order to transit through the enzootic cycle (Caimano et al., 2016).

Overall, a substantial fraction of our current knowledge of gene regulation is supported by the initial microarray and RNA-seq studies, as these significantly contributed to our understanding of differentially expressed $B$. burgdorferi genes that might function in the adaptation of spirochetes to diverse environments in vivo. A collection of molecular tools has been developed (Gilbert et al., 2007; Brisson et al., 2012; Samuels et al., 2018), which should foster new studies delineating the regulatory mechanisms of $B$. burgdorferi genes important for interaction and persistence in the tick environment (Alverson et al., 2003; Caimano et al., 2005; Caimano et al., 2007; Lybecker and Samuels, 2007; Xu et al., 2007) (see also Radolf and Samuels, 2021). Further work is certainly needed to understand the intrinsic signal transduction pathways in spirochetes, as well as the details of the environmental factors that influence borrelial gene expression in ticks.

\section{$B$. burgdorferi genes known to function in ticks}

The $B$. burgdorferi genome encodes approximately 1,780 genes that are distributed among a single chromosome and 21 plasmids (Fraser et al., 1997; Casjens et al., 2000; Casjens et al., 2011; Schutzer et al., 2011; Casjens et al., 2012) (see also Radolf and Samuels, 2021). The vast majority of these genes have been annotated as "hypothetical proteins", as they have little resemblance to known proteins in existing databases, and could therefore possibly carry out specialized functions in the spirochete's enzootic life cycle (Fraser et al., 1997; Casjens et al., 2000). Previous efforts have focused on identifying the borrelial genes that are selectively upregulated at specific phases of the spirochete life cycle. As discussed above, microarray studies of the transcriptome profiling of cultured $B$. burgdorferi could identify genes that exhibit differential 
expression in response to environmental changes and are relevant to its life cycle and transmission through ticks. Indeed, mutagenesis studies indicate that preferentially regulated $B$. burgdorferi gene products (Grimm et al., 2004b; Pal et al., 2004b; Yang et al., 2004; Li et al., 2007b; Neelakanta et al., 2007; Radolf et al., 2012) could serve important functions in supporting the natural cycle of the spirochete. The following sections describe $B$. burgdorferi genes that are known to be highly expressed in the arthropod vector, many of which are thought to be essential in ticks (Grimm et al., 2004b; Pal et al., 2004b; Yang et al., 2004; Munderloh and Kurtti, 2005; Revel et al., 2005; Rosa et al., 2005; Li et al., 2007a; Li et al., 2007b; Pal et al., 2008a; Radolf et al., 2012; Kung et al., 2013). A recent study utilizing a genome-wide screen also identified a novel set of genes required for $B$. burgdorferi survival in the Ixodes vector (Phelan et al., 2019); many of these genes are encoded on plasmids, including ospAB, $o s p C$, ospD, and bbe16, or on the chromosome, such as $d p s$ and la7.

\section{B. burgdorferi plasmids}

The $B$. burgdorferi genome contains nine circular (cp) and 12 linear (Ip) plasmids (Fraser et al., 1997; Casjens et al., 2000) (see also Radolf and Samuels, 2021). Several studies have indicated that specific plasmids are indispensable for $B$. burgdorferi survival in ticks (Purser and Norris, 2000; Grimm et al., 2005; Rosa et al., 2005; Stewart et al., 2005). As noted earlier, microarray studies have demonstrated that, compared to chromosomal genes, the expression of plasmid-encoded genes is more responsive to environmental changes, suggesting that they have pivotal roles in spirochete survival in diverse environments (Ojaimi et al., 2002; Brooks et al., 2003; Tokarz et al., 2004; Caimano et al., 2007; Iyer et al., 2015). B. burgdorferi isolates that lack certain plasmids reinforce the roles of plasmid-encoded genes in the spirochete life cycle in nature. While two linear plasmids, Ip25 and Ip28-1, were required for borrelial persistence in the mammalian host, only Ip25 was found to be essential for tick infection (Purser et al., 2003; Grimm et al., 2004a; Strother et al., 2005; Strother and de Silva, 2005). bbe22 on Ip25 encodes for a nicotinamidase that is most likely essential to the biosynthesis of nicotinamide adenine dinucleotide. The complementation of bbe22 alone was sufficient to restore the ability of spirochetes lacking Ip25 to infect mice (Purser et al., 2003), whereas bbe22 complementation only partially restored tick infectivity (Strother and de Silva, 2005).
B. burgdorferi that was deficient in Ip28-4 also displayed reduced abilities to persist in ticks and transmit to mice (Strother et al., 2005). The same study also determined that the plasmids Ip5, Ip28-1, and $\operatorname{cp} 9$ were not required for spirochete infectivity in the tick gut. Additionally, $B$. burgdorferi lacking the plasmid Ip36 showed no survival defects in ticks, while murine infectivity was significantly compromised (Jewett et al., 2007). Individual genes carried on the same plasmid may have selective host- or vector-specific roles. For example, genes on the plasmid Ip54 include ospA, which is essential in ticks (Yang et al., 2004), and $d b p A B$, which is important in mice (Liang et al., 2004; Shi et al., 2006; Shi et al., 2008). Microarray studies also indicated the differential expression of genes from many of the $B$. burgdorferi plasmids, most notably Ip54, when spirochetes were grown in the presence or absence of mammal-specific factors, such as blood, or when cultured within a DMC (Brooks et al., 2003; Tokarz et al., 2004; Caimano et al., 2007; lyer et al., 2015).

\section{osp $A$ and $o s p B$}

Borrelial genes osp $A$ and $o s p B$ constitute a single operon and encode some of the most abundant outer membrane lipoproteins of $B$. burgdorferi. OspA in particular is shown to interact with multiple host receptors, such as tick receptor TROSPA (Pal et al., 2004a) and plasminogen (Fuchs et al., 1994). Both osp $A$ and osp $B$ show vector-specific expression in the Borrelia life cycle, with both exhibiting upregulation when spirochetes exit an infected mammalian host and migrate to feeding Ixodes ticks (de Silva et al., 1996; de Silva and Fikrig, 1997; Schwan and Piesman, 2000; Schwan, 2003; Fikrig et al., 2004; Neelakanta et al., 2007). Recombinant OspA and OspB specifically adhere to the tick gut, suggesting that these outer surface lipoproteins are important for spirochete adaptation within the gut (Pal et al., 2000; Fikrig et al., 2004). The experimental transfer of non-borreliacidal OspA or OspB antibodies into the murine host prevented the tissue adherence of spirochetes in feeding ticks in vivo, further implicating these proteins in the colonization of Borrelia in the tick gut (Pal et al., 2001). An ospAB null mutant has also been generated and used in tick-mouse infection studies (Yang et al., 2004), where it retained full murine infectivity and pathogenicity, but was unable to infect ticks. OspA/Bdeficient $B$. burgdorferi migrated from infected mice into ticks, but failed to survive in the feeding tick gut, reinforcing the critical role of the ospAB operon in the maintenance of Borrelia in ticks. An OspB-deficient $B$. 
burgdorferi isolate was generated, and infection studies further demonstrated that $\mathrm{OspB}$ is also involved in the colonization and persistence of spirochetes in the arthropod vector (Neelakanta et al., 2007). These experiments demonstrate the importance of both OspA and OspB in B. burgdorferi colonization in the tick gut.

\section{ospC}

OspC is a prominent outer membrane lipoprotein of $B$. burgdorferi that is induced in ticks during the transmission of spirochetes from the feeding vector to the host (Schwan et al., 1995). ospC is the archetype of RpoS-dependent genes that are associated with tick transmission and host infection (Hubner et al., 2001; Yang et al., 2003; Fisher et al., 2005). Studies with ospC deletion mutants have demonstrated that the gene product is essential for infecting the murine host (Grimm et al., 2004b; Pal et al., 2004b; Dunham-Ems et al., 2012). However, the exact role of OspC in the borrelial transmission cycle through ticks warrants further investigation, as there are conflicting results about the phenotype of ospC mutants in ticks. In one study, the ospC null mutant failed to invade $I$. scapularis salivary glands in significant numbers, and was unable to establish infection in the mammalian host (Pal et al., 2004b). Subsequent studies showed that OspC binds a tick salivary gland protein, Salp15, and that the OspC-tick protein interaction facilitated the establishment of spirochete infection in mice (further discussed below). A study involving $B$. afzelii, which is prevalent in Europe and Asia and is transmitted by Ixodes ticks, also supports the notion that OspC is critical for spirochete dissemination from the tick gut to the salivary gland (Fingerle et al., 2007). The complementation of a naturally-occurring ospC mutant with a wild-type copy of the ospC gene resulted in more efficient migration to the salivary glands (Fingerle et al., 2007). Another group independently created a series of ospC mutants and assayed them in tick-mouse infection studies (Grimm et al., 2004b; Stewart et al., 2006; Tilly et al., 2006; Tilly et al., 2007). Their results showed that OspC is required for establishing infection in the murine host; however, ospC deletion had no influence on the migration of $B$. burgdorferi from the tick gut to the salivary gland. A more recent study also demonstrated that Borrelia requires one or more RpoS-dependent genes to migrate through the midgut, although OspC function is not required for the process, as it exclusively functions within the mammal (Dunham-Ems et al., 2012). Therefore, results indicating disparate phenotypes of OspC deletion are likely due to the variations in the experimental approaches to tick infection (microinjection versus immersion infection), spirochete detection modalities, and the use of different isolates of $B$. burgdorferi (strain 297 versus B31), all of which may have contributed to the overall divergent results. The kinetics of pathogen dissemination from the tick gut to the salivary gland could also vary among isolates. Finally, host-derived plasminogen, which is required for efficient spirochete dissemination through ticks (Coleman et al., 1995; Coleman et al., 1997), also is known to bind OspC (Lagal et al., 2006; Onder et al., 2012). Nonetheless, further studies are needed to clarify how the specificity of interactions between the same spirochete antigen, such as $\mathrm{OspC}$, with multiple host or vector molecules, such as plasminogen or Salp15, contributes to borrelial infection. OspC has recently been implicated in various additional functions within mammals that support spirochete survival, such as an antiphagocytic factor (Carrasco et al., 2015), binding to the complement component C4b (Caine et al., 2017), or joint invasion and colonization in a strain-specific manner (Lin et al., 2020).

\section{dps/napA/bicA}

One of the $B$. burgdorferi chromosomal genes that displays regulated expression in the borrelial enzootic cycle is bb0690, which encodes a protein similar to the DNA-binding protein of the starved bacteria (Dps) family of proteins ( $\mathrm{Li}$ et al., 2007b), also known as NapA and BicA (Wang et al., 2012). The protein represents the ortholog of bacterioferritin (Rivera, 2017) fused to a copper-binding metallothionein-like domain, as described in pathogenic Mycobacteria (Gold et al., 2008). dps expression is low throughout $B$. burgdorferi infection in mice but is high during tick intermolt periods. Notably, its expression is repressed in spirochetes during recovery from starvation in vitro (Drecktrah et al., 2015). Dps-deficient spirochetes retained full murine infectivity, readily migrated to feeding arthropods, and persisted in replete ticks. The mutant, however, failed to survive throughout the extended intermolt periods of resting I. scapularis, indicating that Dps is critical to the persistence of spirochetes in unfed ticks ( $\mathrm{Li}$ et al., 2007b). The protein was later suggested to sequester iron and copper, thus promoting spirochete survival in vivo via the detoxification of metal ions, which the pathogen may encounter during its natural life cycle (Wang et al., 2012). 
ospD

OspD is an outer membrane lipoprotein of $B$. burgdorferi that shows tightly regulated expression in the spirochete life cycle. ospD, in general, exhibits elevated expression in ticks as compared to mice ( $\mathrm{Li}$ et al., 2007a). Two studies examined ospD expression in select stages of the tick-mouse infection cycle of $B$. burgdorferi ( $\mathrm{Li}$ et al., 2007a; Stewart et al., 2008). Although the results from these studies differ in their kinetics of $o s p D$ induction, both show that $0 s p D$ transcripts are significantly expressed in a narrow time window that corresponds to the phase of tick detachment from the host after feeding. An OspD-deficient isolate of $B$. burgdorferi was created, and subsequent examination of the mutant phenotype in mice indicated that OspD has no obvious influences on $B$. burgdorferi survival in the murine host, or on spirochete acquisition by ticks (Li et al., 2007a). Recombinant OspD binds to tick gut lysates in vitro, suggesting the protein's role in spirochete adherence to tick tissue (Li et al., 2007a). However, while the ospD mutant has a reduced capacity for attachment to the tick gut in vivo, this does not influence subsequent spirochete transmission during a second blood meal. Taken together, these data suggest that OspD may have a secondary or supportive role in $B$. burgdorferi persistence within ticks (Stewart et al., 2008).

\section{bptA}

BptA, annotated as bbe16, is a lipoprotein that is possibly surface-exposed. bptA is located on the plasmid Ip25, which has been closely associated with Borrelia infectivity (Purser and Norris, 2000; Purser et al., 2003; Strother et al., 2005; Strother and de Silva, 2005). A microarray analysis first identified that bbe16 is a differentially expressed gene, with upregulation when $B$. burgdorferi was cultivated in DMC, as compared to spirochetes grown in culture similar to the environment of fed ticks (Revel et al., 2002). Later studies showed that bptA is selectively expressed in culture conditions mimicking the tick, suggesting its functional role in spirochete persistence in the vector (Revel et al., 2005). In vivo analyses of infectious isolates of bptA mutants and complemented isolates demonstrated a requirement for BptA in borrelial persistence within ticks (Revel et al., 2005). The exact function of the protein in the $B$. burgdorferi natural cycle, however, remains to be elucidated. la7

B. burgdorferi gene la7, annotated as bb0365, encodes P22, which is also known as lipoprotein LA7 (Lam et al., 1994; Grewe and Nuske, 1996). la7 is produced in the mammalian host (von Lackum et al., 2007) and is highly upregulated in spirochetes upon their entry into feeding ticks ( $\mathrm{Pal}$ et al., 2008a). Mutant spirochetes lacking la7 do not differ from the parental isolates in the establishment of murine infection (Pal et al., 2008a). When naïve ticks engorge on spirochete-infected mice, the la7 mutant enters ticks, but displays markedly decreased survival within feeding ticks, as compared to wildtype $B$. burgdorferi. LA7 may, therefore, be important for spirochete survival in feeding arthropods. A recent analysis of the high-resolution structure of LA7 will likely contribute to our understanding of the biological function of the protein (Brangulis et al., 2020a).

\section{Additional genes}

Specific sets of genes, located either on plasmids or the chromosome, show induced expression in ticks; a few of these have already proven to be of functional significance. Many of these proteins may be involved, either directly or indirectly, in interactions with tick molecules, thereby supporting spirochete survival in the vector, as discussed below. Additional borrelial genes have also been identified as being expressed in vivo, although they lack essential supportive roles. $B$. burgdorferi mutants were generated with a lack of luxS (Hubner et al., 2003; Tilly et al., 2004) or chbC (Hubner et al., 2003; Tilly et al., 2004), whose gene products are implicated in a quorum sensing pathway and other potential biochemical roles (Hubner et al., 2003; Tilly et al., 2004) or the transport of the tick cuticle component chitobiose, respectively. The functions of luxS or chbC are, however, not essential for spirochete persistence in ticks, nor during the natural infection cycle (Hubner et al., 2003; Tilly et al., 2004). More recently, a CdnL-type CarD regulator in $B$. burgdorferi, termed as LtpA, has been shown to support pathogen survival in ticks (Chen et al., 2018). A Borrelia protein annotated as BBE31, the crystal structure of which recently was solved (Brangulis et al., 2020b), is known to aid spirochete movement from the tick gut to the hemolymph during spirochete transmission (Zhang et al., 2011). A surface-exposed borrelial protein, enolase, has been shown to support the interaction of $B$. burgdorferi with plasminogen (Floden et al., 2011; Toledo et al., 2011; Nogueira et al., 2012), contributing to pathogen survival within feeding ticks (Nogueira et al., 2012). Another regulatory protein, annotated as BBD18, is thought to 
promote spirochete acquisition in ticks, via the regulation of RpoS (Hayes et al., 2014). A polyamine uptake system, termed as PotABCD and encoded by bb0639-0642, likely supports the vector phase of borrelial replication and survival (Bontemps-Gallo et al., 2018). The BpuR DNA/RNA-binding protein in $B$. burgdorferi (Jutras et al., 2013), which influences the translation of superoxide dismutase, has been shown to undergo preferential expression in ticks and to enhance spirochete survival in the vector (Jutras et al., 2019). One of the borrelial virulence determinants, annotated as Lmp1, is a surfaceexposed and potentially multi-domain protein that is involved in various functions in spirochete infectivity (Yang et al., 2009; Yang et al., 2010). Recent studies indicate that Lmp1 contributes to host-pathogen interactions, including spirochete transmission from ticks to mammals (Zhuang et al., 2018), and possibly spirochete dissemination through tick tissues (Koci et al., 2018), which requires essential contributions from both the $\mathrm{N}$-terminal and middle regions of Lmp1. The gene encoding BBA57 is constitutively expressed during the Borrelia infectious cycle involving both mice and ticks (Yang et al., 2013). Although it is unclear whether or how the protein supports $B$. burgdorferi infection in ticks, it is known to facilitate early spirochete infection in mice through the impairment of the host complement and neutrophilderived antimicrobial defense mechanisms (Bernard et al., 2018).

The recent development of genetic tools has allowed researchers to create specific mutants of $B$. burgdorferi and to identify borrelial proteins that function at different stages in the vector phase of the spirochete life cycle (Radolf et al., 2012; Samuels et al., 2018). As B. burgdorferi spends a significant part of its life inside the arthropod, additional genes that are important in ticks are likely to be identified. Highthroughput expression analyses, such as quantitative RT-PCR and RNA amplification-based microarray assays, have the potential to reveal genes that are highly expressed in ticks and may perform specialized functions in the complex enzootic life cycle of $B$. burgdorferi. In fact, with an ingenious use of genetic tools and a high-throughput screen, a recent seminal study detailed the identification of a set of novel genes that are required for borrelial survival in Ixodes ticks (Phelan et al., 2019). It was shown that many of these essential genes encode proteins of unknown function, membrane-associated proteins, or lipoproteins, which could support hostpathogen interactions or other important aspects of spirochete biology. B. burgdorferi harbors a homolog of the hibernation promotion factor, bb0449, although the gene function has been characterized as redundant for spirochete survival in vivo, including within the tick (Fazzino et al., 2015). The Relibu, the RelA/SpoT homolog in B. burgdorferi, regulates the stringent response and global gene expression in spirochetes and is required for pathogen survival in the tick (Drecktrah et al., 2015). Finally, the ssrS gene encoding the Bb6S RNA of $B$. burgdorferi, which is considered as one of the first regulatory RNAs, has been shown to control the expression of multiple lipoproteins involved in host infectivity (Drecktrah et al., 2020).

\section{Molecular interfaces: interactions of microbial and vector gene products}

Regardless of the nature of the ecological relationship between a microbe and its host, the development of specific molecular interactions is an essential prerequisite for the survival of the microbe in vivo (Finlay and Cossart, 1997; Dale and Moran, 2006). Mainly based on the vector-specific expression of limited $B$. burgdorferi gene products, scientists have uncovered a handful of discrete interactions between the spirochete and tick vector that are summarized below. These studies have established that certain borrelial proteins contribute to the maintenance of the spirochete infection cycle within ticks, either directly or via molecular interactions with specific vector receptors.

\section{Interaction of $\mathrm{B}$. burgdorferi with tick gut proteins TROSPA}

The tick receptor for OspA (TROSPA), which is predominantly expressed in the gut of $I$. scapularis, specifically interacts with $B$. burgdorferi OspA (Pal et al., 2004a). This receptor-ligand interaction is further explained by the findings that TROSPA co-localizes with OspA in the tick gut in vivo, and that OspA specifically bound recombinant TROSPA in a series of in vitro assays (Pal et al., 2004a). It was later shown that the N-terminal portion of TROSPA, which contains a putative transmembrane domain, is not involved in the OspA interaction, and that charges on the TROSPA protein influence its interaction with OspA (Figlerowicz et al., 2013). Interestingly, TROSPA expression within the tick was upregulated during spirochete infection and decreased during engorgement, suggesting its regulation by extrinsic cues. When uninfected ticks parasitized infected mice that had been passively administered TROSPA antisera, the acquisition of $B$. burgdorferi by the ticks 
was significantly reduced, as compared to those that fed on infected mice treated with pre-immune sera. TROSPA-immunized ticks also demonstrated a reduced capacity for pathogen transmission. Similarly, the RNA interference of TROSPA in nymphal ticks significantly diminished their ability to acquire $B$. burgdorferi from infected mice (Pal et al., 2004). The spirochetes appear to colonize the tick gut by adhering to TROSPA through OspA, which highlights the importance of this interaction in supporting the borrelial infection cycle in ticks. Nevertheless, the native function of TROSPA in the arthropod is currently unknown. TROSPA is not consistently expressed in all stages of $I$. scapularis, and its expression is highly influenced by environmental signals, such as blood meal engorgement or $B$. burgdorferi infection. These observations indicate a developmental function, rather than a housekeeping role, of TROSPA in tick biology.

Dystroglycan-like protein (ISDLP)

I. scapularis dystroglycan-like protein (ISDLP) is a $B$. burgdorferi-interacting tick gut protein with similarities to the dystroglycan family of proteins (Coumou et al., 2016). ISDLP is expressed on the gut epithelial surface and is induced during tick feeding and by borrelial infection. Additionally, this tick protein can bind to $B$. burgdorferi, and its knockdown by RNA interference has been shown to impair pathogen transmission, suggesting an important role in spirochete dissemination from ticks to mice.

\section{TRE31 and Ixofin3D}

Two tick gut proteins were described that support the dissemination of $B$. burgdorferi from the tick gut, particularly during pathogen transmission to the host. TRE31 was characterized as a tick gut protein that specifically interacts with BBE31, one of the borrelial outer surface lipoproteins (Zhang et al., 2011). The gene is preferentially expressed in the tissues of fed ticks, including the gut, hemolymph, and salivary glands. BBE31 antiserum impaired spirochete migration from the tick gut to the salivary glands, consequently attenuating murine infection by ticktransmitted $B$. burgdorferi. The silencing of tre31 also lowered the pathogen burden in the tick hemolymph. These data indicate that TRE31 plays a role in enabling spirochete movement by interacting with BBE31. The crystal structure of BBE31 was recently solved, which will be important for a better understanding of the specific ligand-receptor interactions that support $B$. burgdorferi movement in the tick (Brangulis et al., 2020b). Additionally, Ixofin3D represents another tick gut protein that is relevant to pathogen dissemination, with similarities to putative fibronectin type III domain-containing proteins (Narasimhan et al., 2014a). As with TRE31, the antibody or RNA interference-mediated impairment of Ixofin3D resulted in decreased spirochete burdens in the tick salivary glands and in the murine host.

\section{Dual oxidase}

A dual oxidase in the tick gut (Duox), which is a member of the NADPH oxidase family, is involved in the maintenance of gut microbial homeostasis and the genesis of an acellular gut barrier called the dityrosine network (DTN) (Yang et al., 2014). The DTN develops from the tyrosine cross-linking of the extracellular matrix in I. scapularis ticks during blood meal engorgement. This Duox-mediated barrier influences the survival of $B$. burgdorferi in the gut, as an impaired DTN in duox-knockdown ticks can result in reduced levels of pathogen persistence within ticks. The absence of complete DTN formation in the tick gut activates a specific tick innate immune pathway, via the induction of nitric oxide synthase, which ultimately reduces the spirochete burden in the arthropods (Yang et al., 2014). Deeper understandings of the tick innate immune responses and the related vector-pathogen interactions, such as the one orchestrated by Duox, along with their contributions to microbial survival, are critical to the development of new interventions against tick-borne infections, including Lyme borreliosis.

\section{PIXR}

A Reeler domain-containing tick gut protein was described that influences the colonization of $B$. burgdorferi in the tick gut (Narasimhan et al., 2017). The gene product, which was termed "Protein of $l$. scapularis with a Reeler domain" (PIXR), is induced by spirochete infection. Both the knockdown of pixr via RNA interference and the antibody-mediated inhibition of PIXR reduced the ability of $B$. burgdorferi to infect the tick gut. Notably, PIXR was shown to be involved in biofilm formation, both in vitro and in vivo. The impairment of the PIXR function in ticks also had diverse effects on intrinsic and extrinsic elements within the arthropods, including their gut microbiome, metabolome, and immune responses. Additionally, PIXR has a proposed role in tick developmental biology, as the abrogation of its function impaired larval molting (Narasimhan et al., 2017). Subsequent analyses also revealed that the Ixodes microbiota is 
sensitive to anti-tick immunity, with biofilm formation potentially serving as the microbiome's defensive response to this immunity (Estrada-Pena et al., 2020).

\section{IsCDA}

One of the first detailed characterizations of the Ixodes peritrophic membrane (PM) involved a mass spectrometric analysis of the structure in ticks (Kariu et al., 2013). This revealed information about the $I$. scapularis CDA-like protein, or IsCDA, which is an immunogenic, antigenic, and predominant (60-kDa) component of the PM, with homology to arthropod chitin deacetylase. IsCDA is mainly expressed in the gut and is induced during early tick feeding. Interestingly, the knockdown of IsCDA via RNA interference failed to influence $P M$ formation or spirochete persistence, suggesting nonessential roles of the protein in tick biology and host-pathogen interaction. However, IsCDA immunization selectively impaired B. burgdorferi survival in the gut, but not the rest of the microbial community, implying that crossreactive IsCDA antibodies may influence $P M$ functions relevant to spirochete persistence in ticks. It is therefore speculated that the tick PM plays a preferential role in limiting the persistence of $B$. burgdorferi within the vector.

\section{Interaction of $B$. burgdorferi with tick salivary gland proteins}

Since the discovery of immunodominant antigens that are deposited in the host dermis by feeding ticks, I. scapularis salivary gland proteins (Salps) have been an intense focus of Borrelia research (Das et al., 2000; Das et al., 2001; Francischetti et al., 2005; Ribeiro et al., 2006). Indeed, such so-called salivaassisted transmission (SAT) (Nuttall, 2019) events have been studied in detail for many other vectorborne diseases, and novel salivary gland vaccine targets have been identified, such as for the leishmaniasis infection (Morris et al., 2001; Valenzuela et al., 2001). Many Salps are soluble, feeding-induced, and co-transmitted to the host along with $B$. burgdorferi; thus, these proteins have an opportunity to influence spirochete migration between the vector and host, either directly or indirectly (Ramamoorthi et al., 2005; Rosa, 2005; Radolf et al., 2012). The generation of host immunity against $I$. scapularis salivary gland proteins, particularly those expressed as early as 24 hours after feeding, is sufficient for the impairment of $B$. burgdorferi transmission between ticks and hosts (Narasimhan et al., 2007). The following are examples of tick Salps that influence spirochete infection.

\section{Salp15}

As discussed earlier, OspC is a prominent borrelial outer membrane lipoprotein that is swiftly upregulated during tick transmission (Schwan et al., 1995) and binds the tick salivary gland protein Salp15 (Anguita et al., 2002; Ramamoorthi et al., 2005). The OspC-Salp15 interaction has important functional consequences that impact spirochete transmission and pathogenesis in a multipartite manner, involving the pathogen, vector, and host (Ramamoorthi et al., 2005). B. burgdorferi carries Salp15 (via OspC binding) during its transmission from the tick salivary gland to the murine host, thereby facilitating Borrelia survival within the infected mammal (Anguita et al., 2002). Salp15 specifically binds $B$. burgdorferi OspC and prevents the killing of spirochetes by borreliacidal antibodies in vitro. Thus, the coating of the spirochetes via binding to Salp15 in the tick salivary gland could have important implications for pathogen survival in the host. The binding of Salp15 to Borrelia could potentially mask the exposure of OspC to components of the host immune system, as OspC is shown to be highly immunogenic and is a target of host borreliacidal antibodies (Wilske et al., 1993; Fung et al., 1994; Wilske et al., 1996; Mbow et al., 1999; Liang et al., 2002; Wilske, 2005; Buckles et al., 2006; Earnhart et al., 2007; Earnhart and Marconi, 2007b, a). Additionally, by itself, Salp15 carries host immunosuppressive properties by inhibiting $\mathrm{CD}^{+} \mathrm{T}$ cell activation (Anguita et al., 2002). Thus, OspCbound Salp15 provides further benefits to spirochetes, potentially affording protection against immune cells that infiltrate the tick bite site. Interestingly, the OspC-Salp15 interaction could be beneficial to both the vector and pathogen (Ramamoorthi et al., 2005). B. burgdorferi induces salp15 expression in the salivary glands of feeding arthropods; therefore, borrelial infection may provide survival advantages to the arthropod that produces this protein, as it could promote effective feeding via the binding of Salp15 and plasminogen at the bite site (Coleman et al., 1995; Coleman et al., 1997; Ramamoorthi et al., 2005; Lagal et al., 2006).

\section{Salp25D}

One of the abundant tick Salps, Salp25D (Das et al., 2001), plays an important role in the mammalian host in regards to the acquisition of $B$. burgdorferi by the vector (Narasimhan et al., 2007). The silencing of 
salp25D in Ixodes salivary glands has been revealed to block spirochete acquisition by ticks from infected mice. Salp25D functions as an antioxidant; thus, the Salp25D-mediated detoxification of reactive oxygen radicals at the tick-pathogen-host interface potentially provides a survival advantage to $B$. burgdorferi at the bite site in mice.

\section{Salp20}

In addition to Salp15, which binds to $B$. burgdorferi and contributes to the protection of spirochetes against host immunity, Salp20 has also been shown to protect serum-sensitive strains of Borrelia from lysis in in vitro assays (Tyson et al., 2007). Accordingly, Salp20 may also protect spirochetes from the host complement system within the vector blood meal and during transmission. Salp20 is related to the $I$. scapularis anti-complement (Isac) family of proteins that may block the host alternative complement pathway (Soares et al., 2005; Ribeiro et al., 2006). RNA interference studies have established that $I s a c$ and related family members of tick proteins promote efficient tick feeding and spirochete growth in ticks (Soares et al., 2005).

Tick histamine release factor

Histamine release factor (tHRF) was identified as an Ixodes salivary gland protein induced by $B$. burgdorferi infection (Dai et al., 2010). Recombinant tHRF binds host basophils and stimulates histamine release. Tick saliva, from which tHRF is secreted, is known to induce specific host chemokines, including histamine-releasing cytokine, that favor feeding by ticks (Langhansova et al., 2015). As the expression of tHRF varies in correlation to the rapid feeding phase of the tick, it was speculated that the protein contributes to blood meal engorgement and likely influences spirochete transmission from the arthropod. The RNA interference-mediated knockdown of tHRF impaired tick feeding and also decreased Borrelia levels in the murine hosts (Dai et al., 2010). Vaccination with tHRF reduced both the tick feeding efficiency and $B$. burgdorferi burden in mice. Additionally, it was reasoned that tHRF in ticks serves to facilitate vascular permeability and to increase blood flow to the tick bite site, ultimately favoring their blood meal engorgement (Dai et al., 2010). These data highlight the vaccine potential of tHRF and its ability to interfere with tick feeding and pathogen transmission.
Tick salivary lectin pathway inhibitor

A tick protein designated as tick salivary lectin pathway inhibitor (TSLPI) was found to impair the host complement-mediated killing of $B$. burgdorferi (Schuijt et al., 2011). TSLPI was shown to interfere with the human lectin complement cascade (Wagemakers et al., 2016), which reduced neutrophil phagocytosis and chemotaxis, thus decreasing the lysis of $B$. burgdorferi cells. TSLPI-knockdown ticks, or ticks that fed on TSLPI-vaccinated mice, were unable to transmit the pathogen efficiently. These studies underscore the importance of the lectin complement cascade and associated immune responses (Coumou et al., 2019) in borrelial transmission through lxodes ticks and the establishment of early infection in mammals.

\section{Additional salivary gland proteins}

In a recent study, researchers identified another Ixodes Salp, termed Salp12, which is involved in the vector chemoattractant for the spirochete (Murfin et al., 2019). The gene encoding Salp12 is expressed in the salivary glands and gut. Interference with the function of Salp12 impacted spirochete acquisition by ticks, but not pathogen transmission. In addition to $I$. scapularis Salp15, as detailed in earlier paragraphs, novel Salp15-like immunosuppressant genes were also shown to be produced from the salivary glands of other Ixodes ticks, such as $I$. persulcatus (Mori et al., 2010). Additionally, salivary lipocalins that are differentially expressed during infection with $B$. afzelii are thought to support pathogen transmission to the host (Valdes et al., 2016). A panel of immunogenic proteins in the saliva of $24 \mathrm{~h}-\mathrm{fed}$ female $\mathrm{I}$. scapularis was also identified, some of which may be involved in interactions with $B$. burgdorferi, consequently influencing spirochete transmission through ticks (Lewis et al., 2015).

\section{Interactions with additional tick proteins \\ Dae2}

A novel antibacterial enzyme was discovered to be acquired by Ixodes ticks through lateral gene transfer from a bacterium during the early evolution of ticks and mites. The enzyme, termed Dae2 (domesticated amidase effector 2), shares similarities to peptidoglycan-degrading toxins and specifically limits the proliferation of $B$. burgdorferi in ticks (Chou et al., 2015). Dae2 was also identified as one of the Ixodes antimicrobial effector molecules that are downstream of a newly discovered cross-species interferon signaling pathway. This pathway, which is triggered by the mammalian IFNy that is acquired in the tick 
blood meal, induces a tick Rho-like GTPase in a STAT-dependent manner, ultimately reducing the levels of $B$. burgdorferi via the induction of select antimicrobial proteins, including Dae2 (Smith et al., 2016).

Tick antimicrobial peptides (defensin and others)

Defensins are a well-known class of antimicrobial peptides of innate immunity that are effective against a wide range of pathogens (Ganz, 2003); not surprisingly, Ixodes ticks encode multiple defensinlike genes (Hynes et al., 2005; Smith and Pal, 2014; Gulia-Nuss et al., 2016; Smith et al., 2016), some of which are induced in the gut after infection with $B$. burgdorferi (Sonenshine et al., 2002; Rudenko et al., 2005; Smith et al., 2016) (see also Radolf and Samuels, 2021). Two isoforms (Chrudimska et al., 2011) and six novel putative defensins from $I$. ricinus were identified that may have antimicrobial activity (Tonk et al., 2014b). It is unclear whether defensins play a role in controlling $B$. burgdorferi infection in ticks (Smith et al., 2016); however, two chemicallysynthesized defensin peptides based on I. scapularis tick defensins (Tonk et al., 2014b), termed as Scapularisin-3 and Scapularisin-6, carry potent antiListeria and antifungal activities (Tonk et al., 2014a). Codon-substitution models support the neutral evolution of Ixodes defensins, resulting in its vast gene expansion (Wang and Zhu, 2011). Other than these defensins, the lxodes tick genome also contains genes that encode a diverse array of antimicrobial proteins or peptides (Smith et al., 2016), some with potential anti-B. burgdorferi activities. Tick saliva is reported to possess anti-alarmin effects during the transmission of Borrelia, thereby aiding in the establishment of infection in the host (Marchal et al., 2011). Furthermore, events like blood meal digestion in ticks generate novel peptides with antimicrobial activities (Sonenshine, 1993; Kopacek et al., 2010), and the recent deep sequencing analysis of the $l$. ricinus hemocytome suggests additional genes that may encode still more antimicrobial peptides (Kotsyfakis et al., 2015).

Other Ixodes tick proteins, even ones that are intracellular, are shown to be induced upon $B$. burgdorferi infection in the vector. One such example is a selenoprotein that is involved in the regulation of oxidative and endoplasmic reticulum stress. However, the mechanisms by which intracellular Ixodes proteins support pathogen survival in ticks remain enigmatic (Kumar et al., 2019). Nevertheless, these studies collectively indicate the existence of highly discrete molecular interfaces where specific microbial and vector gene products interact, either directly or indirectly, thus contributing to $B$. burgdorferi survival in a natural enzootic cycle.

\section{Interface between tick immune system and $B$. burgdorferi}

Despite substantial existing knowledge of arthropod innate immunity (Hoffmann et al., 1999; Irving et al., 2001; Hoffmann and Reichhart, 2002; Hoffmann, 2003; Ferrandon et al., 2007; Lemaitre and Hoffmann, 2007; Clayton et al., 2014), the molecular mechanisms by which the Ixodes immune system interfaces with and recognizes invading microbes remain poorly understood. Recent studies suggest that $B$. burgdorferi levels in ticks are affected by the independent knockdown of components from specific immune pathways, providing the first evidence of an active interface between the tick immune system and the agents of Lyme disease (Smith et al., 2016; Shaw et al., 2017; Kitsou and Pal, 2018). Research has also revealed that the gut microbiota associates with the Ixodes immune system, playing critical and influential roles in arthropod biology, including the ability to maintain and transmit $B$. burgdorferi (Narasimhan et al., 2014b; Narasimhan et al., 2017). These studies highlight novel concepts of tick immune responses that probably involve direct and indirect methods of pathogen recognition, including that of B. burgdorferi (Kitsou and Pal, 2018), and therefore incorporate multifaceted interactions between invading microbes and defense responses, as summarized below.

The arthropod immune system likely recognizes microorganisms directly by germ line-encoded, nonrearranging cellular receptors, and controls infection through the rapid generation of microbicidal effector responses (Hoffmann and Reichhart, 2002; Hoffmann, 2003; Ferrandon et al., 2007; Valanne et al., 2011; Myllymaki et al., 2014; Smith and Pal, 2014; Shaw et al., 2018). Recent studies show that the Ixodes immune deficiency (IMD) pathway senses microbial molecular patterns, like that of infectionderived lipids, such as 1-palmitoyl-2-oleoyl-snglycero-3-phosphoglycerol and 1-palmitoyl-2-oleoyl diacylglycerol, or diaminopimelic-type peptidoglycans, which are present in diverse bacterial pathogens including $B$. burgdorferi, ultimately leading to the generation of potent microbicidal responses in ticks (Shaw et al., 2017). The details of such molecular interactions between the tick immune system and spirochete cells or antigens, as well as 
the identity of any tick receptors that recognize microbial molecules, remain unknown. The tick E3 ubiquitin ligase $X$-linked inhibitor of apoptosis (XIAP) has recently been demonstrated to act as a molecular rheostat for the IMD pathway (McClure Carroll et al., 2019).

Studies of Drosophila and mammals also suggest the existence of alternative immune mechanisms, such as indirect or more host-centric immune recognition pathways, for interactions with virulent bacteria. These indirect immune cascades, including effectortriggered immunity (Cui et al., 2015), can sense pathogens or pathogenic-derived effector molecules that modify a host target molecule (Boyer et al., 2011). While examining the molecular mechanism of $B$. burgdorferi acquisition in Ixodes ticks, Smith et al. identified the existence of a novel cross-kingdom signaling cascade, incorporating both the mammalian host and tick vector (Smith et al., 2016). This cascade enables $l$. scapularis to recognize a mammalian cytokine, identified as IFNy, which arrives in ticks via the ingested blood meal and functions as a potent infection cue by interacting with currently unknown tick receptor(s), thus activating microbicidal responses that limit the proliferation of invading spirochetes (de Silva, 2016; Smith et al., 2016). This novel IFNy signaling involves the tick STAT protein, which induces an Ixodes GTPase (termed as IGTPase), as well as multiple borreliacidal effector molecules, including Dae2 (Chou et al., 2015), thereby reducing $B$. burgdorferi persistence in the arthropod (Smith et al., 2016). More recently, tick extracellular vesicles, resulting from exosome and microvesicle biogenesis, have been proposed to manipulate cross-kingdom signaling networks, potentially impacting pathogen spread and colonization in the host (Chavez et al., 2019). While these indirect or host-centric recognition pathways of infection and interaction between the tick immune system and invading microbe are emerging concepts, additional studies are required to enrich our fundamental knowledge of tick immunobiology and host-pathogen interactions.

\section{Microbiome interactions}

In Ixodes ticks, B. burgdorferi resides in the gut, which is also inhabited by diverse microbiota, as indicated by a series of recent studies using either laboratory or wild-collected ticks (Narasimhan and Fikrig, 2015; Bonnet et al., 2017; Swei and Kwan, 2017; Couper and Swei, 2018; Greay et al., 2018; Hernandez-Jarguin et al., 2018; Aivelo et al., 2019;
Landesman et al., 2019; Tokarz et al., 2019). The role of gut microbiota, its interactions with invading pathogens, and the maintenance of immune homeostasis are now well-established concepts in many organisms (Ley et al., 2008; Molina-Cruz et al., 2008; Round and Mazmanian, 2009; Hooper et al., 2012; Buchon et al., 2013; Kamada et al., 2013). The Ixodes gut microbiota was recently described as having an important role in the persistence of tickborne pathogens like $B$. burgdorferi (Narasimhan et al., 2014b). The presence of pathogens in the tick gut, along with their possible interactions with resident gut microbiota, could impair tick structural barriers, such as the peritrophic matrix, via the modulation of tick proteins and/or specific immune signaling pathways. These complex interactions, involving diverse pathogens, gut microbiota, and tick proteins, essentially shape the survival of spirochetes in the vector (Narasimhan et al., 2014b; Abraham et al., 2017). Further studies of tick-pathogen and immunome-gut microbiome interactions, particularly how they impact spirochete persistence, will be necessary to enhance our knowledge of tick-borne infections. The use of new experimental approaches, such as dysbiosis (Narasimhan et al., 2014b), aposymbiotic ticks, and the artificial feeder system, including ones recently developed (Oliver et al., 2016; Koci et al., 2018), which can eliminate unwanted host factors and allow an unprecedented degree of empirical manipulation, will be especially valuable for these investigations.

\section{Ixodes genomics}

Two separate studies provided initial information about the complete genome sequence of $I$. scapularis, both in ticks (Gulia-Nuss et al., 2016) and an Ixodes cell line (Miller et al., 2018). The exploration of the Ixodes genome offers new avenues for scientific investigation and should reveal novel features of the microbe-vector interaction. However, further research on this subject largely awaits major developments in gene manipulation tools and the pursuit of additional genome sequencing efforts, which are summarized below.

\section{Gene manipulation}

Stable methods of gene manipulation are welldeveloped in other arthropod vectors, such as in mosquitoes (Catteruccia et al., 2000; Catteruccia, 2007), and are influenced by the development of advanced genetic tools in the Drosophila (Venken and Bellen, 2005). Gene manipulation in ticks remains in its infancy because few of the available 
genetic tools are readily applicable. RNA interference (RNAi) is now viewed as the only possible genesilencing technique in ticks (de la Fuente et al., 2007a), although the knockdown effects are transient. Unfortunately, unlike many other arthropods (Bucher et al., 2002; He et al., 2006; Khila and Grbic, 2007), the use of parental RNAi to introduce stable RNAi effects in offspring has brought limited success in ticks. Additional formidable challenges include the lack of information about tick embryology and the tick genome; further progress in these areas would stimulate the development of more advanced gene manipulation methodologies. However, the long life span and slow post-embryonic development of Ixodes ticks will pose serious problems for the phenotypic analysis of mutants after the genome has been manipulated. These efforts will be further complicated by the sensitivity of $I$. scapularis embryonic development, including premolt and preoviposition development, to environmental conditions, such as temperature (Heath, 1979; Ogden et al., 2004). Nevertheless, I. scapularis cell lines (Munderloh et al., 1994) are available to the research community, which should allow us to optimize the manipulation of the tick genome in cell culture.

Whole genome sequence

The I. scapularis Genome Project (IGP), a collaborative effort between the international community of tick researchers and genome sequencing centers, was initiated more than a decade ago with the support of the National Institutes of Health (Hill and Wikel, 2005; Pagel Van Zee et al., 2007), with the intention of performing whole genome sequencing of $I$. scapularis. More than 18 million trace reads, representing approximately a five-fold coverage of the genome, have been deposited thus far at the National Center for Biotechnology Information (NCBI) Trace Archive (Pagel Van Zee et al., 2007). In addition, 20 Ixodes bacterial artificial chromosome (BAC) clones, 370,000 BAC-end reads, and more than 80,000 expressed sequence tags (ESTs) have been sequenced. The sequencing, assembly, and annotation of a six-fold coverage of the Ixodes genome were expected by 2008, but these efforts took longer due to the large genome size, genomic complexity, and presence of extensive repetitive DNA in I. scapularis (Ullmann et al., 2005; Geraci et al., 2007). In 2016, the annotated whole genome sequencing of the $I$. scapularis tick was published (Gulia-Nuss et al., 2016), which was subsequently followed by a draft genome sequence for the I. scapularis ISE6 cell line (Miller et al., 2018). The study that addressed the whole genome analysis of ticks annotated approximately $57 \%$ of the genome, indicating the presence of at least 20,486 proteincoding genes, with a notable occurrence of gene families associated with tick-host interactions. Despite these seminal efforts, our knowledge of the tick genome remains limited, although more sophisticated sequencing tools are increasingly available and can be utilized to construct a complete tick genome atlas. More recently, high-throughput long-read DNA/RNA sequencing (Amarasinghe et al., 2020), single-cell and single-nucleus RNAsequencing methods (Ding et al., 2020), and chromosome conformation capture methods (Lieberman-Aiden et al., 2009) have provided unprecedented views of the genome, including that of arthropod vectors, particularly the three-dimensional organization of chromosomes, genomes, and genome-wide chromatin contacts (Dudchenko et al., 2017; Wang et al., 2018), which are recognized as crucial aspects of gene regulation (Bonev et al., 2017). The wealth of information from these genome studies is expected to have a high impact on future gene manipulation technologies and will contribute to our understanding of vector biology, including pathogen survival and transmission through lxodes ticks (de la Fuente et al., 2016).

\section{Ixodes transcriptomics}

The availability of next-generation sequencing technologies, such as genome-wide RNAsequencing (RNA-Seq) (Wang et al., 2009; Stark et al., 2019) and single cell transcriptomics (La Manno, 2019; Skinnider et al., 2019), has provided a unique opportunity to study gene expression in Ixodes ticks, including its relevance to vector-pathogen interactions, not only on a high-throughput basis, but also at the levels of the single cell, tissue, or whole organism. Conventional and targeted approaches, like subtractive hybridization (Narasimhan et al., 2017) or quantitative RT-PCR (Smith et al., 2016), have previously been utilized for the identification of tick transcripts that are modulated during borrelial infection. The recent progress of next-generation sequencing, now with capabilities for short or long reads and de novo genome transcriptome analysis (Schwarz et al., 2013), has allowed for a robust and global analysis of the lxodes genes that are modulated during the entry, persistence, and exit of $B$. burgdorferi through ticks. Over the past decades, a number of studies have addressed Ixodes transcriptomics in the presence or absence of tick- 
borne pathogens, including in the gut (Perner et al., 2016), salivary glands (Francischetti et al., 2005; McNally et al., 2012; Schwarz et al., 2013), hemocytes (Kotsyfakis et al., 2015), and whole ticks (Charrier et al., 2018) or cell lines (Weisheit et al., 2015; Alberdi et al., 2016; Mansfield et al., 2017), which is important for understanding the unusual biology of ticks, such as their blood meal digestion, development, and host-pathogen interactions. A recent meta-analysis of published RNA-Seq studies compared the genetic variations between wild strains and laboratory strains of $I$. ricinus (Charrier et al., 2018). Together, these data will enrich our knowledge of the biology of an ancient arthropod vector and will inform the development of novel control strategies against tick bites or tick-transmitted infections.

The integration of transcriptomics data with other available information, like tick biology and proteomics (Ribeiro and Francischetti, 2003), as well as experimental vaccination trials, will aid in the identification of novel tick protective antigens and possibly future vaccines (Contreras et al., 2016; Contreras et al., 2019). This is particularly important, as Ixodes ticks can parasitize almost any vertebrate class across the globe and are second only to mosquitoes as vectors of serious human infectious diseases. The tick salivary gland transcriptome (Ribeiro and Francischetti, 2003; Francischetti et al., 2005; Ribeiro et al., 2006) will foster research on the roles of additional tick salivary gland proteins that support $B$. burgdorferi infection and transmission to the host. The salivary gland transcriptome has identified transcripts encoding proteins with signature functional domains, including basic-tail and Kunitz, as well as proline-rich peptides, metalloproteases, and novel proteins with similarities to disintegrins, histamine-binding proteins, anti-complement proteins, and a neuropeptide-like protein (nlp-31) that may have antimicrobial activity (Francischetti et al., 2005). The further characterization of these proteins and their functions will greatly contribute to our understanding of host immunity and the development of vaccines against both ticks and the pathogens that they transmit.

\section{Ixodes proteomics and metabolomics}

Similar to transcriptomics, other high-throughput "omics" approaches, such as proteomics and metabolomics, provide useful information about the overall protein diversity and steady-state levels of small molecules in cells or tissues, which is insightful in regards to tick biology and the discovery of vaccine or therapeutic targets (Contreras et al., 2019). High resolution LC-MS/MS (Seger and Salzmann, 2020), ITRAQ (isobaric Tags for Relative and Absolute Quantitation) (Luo and Zhao, 2012), and shotgun proteomics (Lisacek et al., 2006) have allowed for more sensitive and accurate analyses of proteomics and metabolomics in tick-borne infections. These techniques have been applied to the study of pathogens like $B$. burgdorferi, including the characterization of the proteome in the borrelial outer membrane and the classification of protein-protein interactions (Yang et al., 2011; Yang et al., 2018), in addition to tracking the sources of blood meals (Onder et al., 2014) and analyzing the proteome in the tick vector (Di Venere et al., 2015; lovinella et al., 2016) or in infected tick cells (Weisheit et al., 2015; Grabowski et al., 2016), as well as the immunoproteomic identification of tick antigens (Vu Hai et al., 2013). These experimental approaches have been applied to a system-level analysis of proteome complexity in the Ixodes gut and salivary glands (Schwarz et al., 2014), which are the organs relevant to blood meal engorgement, vector interactions, and the colonization of tick-borne pathogens. Another study used ITRAQ to identify at least 12 salivary gland proteins in $I$. ricinus that were modulated in the presence of various Borrelia strains (Cotte et al., 2014). As the post-translational modification of proteins is critical to protein function, including hostpathogen interactions, bioanalytical methods for glycobiology were developed, such as those based on mass spectrometry (Vechtova et al., 2018), although they have not yet been used in studies addressing tick interactions with the spirochete. Proteomic comparative studies of various tick cell lines also were reported, which proved to be indispensable for tick research (Munderloh et al., 1994; Munderloh and Kurtti, 1995), as the tools allow for cell lines to be used as controlled experimental systems in the study of tick-pathogen interactions (Loginov et al., 2019). Using gas chromatography coupled to a mass spectrometry-based approach, a recent study explored the differences between the metabolic profiles of $B$. burgdorferi-infected and naïve $I$. scapularis nymphal ticks during blood meal engorgement (Hoxmeier et al., 2017). Additional studies on tick-pathogen metabolic interactions (see review (Cabezas-Cruz et al., 2019)) are certainly warranted, as they will contribute both to our understanding of the complex interactions between $B$. burgdorferi and Ixodes ticks, and to the development of novel interventions against tick-borne infections. 


\section{Interaction-blocking Lyme disease vaccines}

During infection in mammals, including humans (Radolf and Samuels, 2021), B. burgdorferi enters the skin at the site of the tick bite, typically resulting in a dermal lesion called erythema migrans (Nadelman and Wormser, 1998; Wormser et al., 2006), although almost $30 \%$ of human subjects fail to display the lesion. The diagnosis of Lyme disease (Marques, 2015) (see also Radolf and Samuels, 2021), especially during early infection, still remains a challenging task, due to the clinical manifestations it has in common with other febrile diseases, in addition to variations in the immune responses of infected individuals. The available antibiotic treatment usually resolves clinical symptoms, if administered in the early stages of infection. However, persistent or relapsing symptoms (e.g., fatigue, musculoskeletal pain, cognitive difficulties, etc.) later develop in a subset of patients; these symptoms are collectively referred to as chronic Lyme disease or antibiotic treatment-resistant Lyme arthritis, a condition otherwise termed as post-treatment Lyme disease syndrome (PTLDS) (Marques, 2008; Aucott et al., 2013). The pathogenesis and treatment of PTLDS remain obscure (Radolf and Samuels, 2021). These factors, combined with a remarkably high incidence of Lyme disease (Mead, 2015) (see also Radolf and Samuels, 2021), further underscore the need for the development of effective preventive measures, such as vaccines to combat infection (Gomes-Solecki et al., 2020), which is the research focus in many laboratories. Such studies aim to investigate the protective efficacy of potential vaccine candidates in animal models of Lyme borreliosis (Radolf and Samuels, 2021), targeting specific spirochete and/or tick antigens that are essential for pathogen transmission and/or persistence, as exemplified in the following sections (Radolf and Samuels, 2021).

\section{Antigens based on spirochetes}

Understanding the molecular details of the $B$. burgdorferi life cycle, particularly in the arthropod vector, is likely to support the development of novel Lyme disease vaccines that are based on spirochete antigens. This notion is supported by the success and mechanism of protection afforded by the original human vaccine against Lyme disease (Fikrig et al., 1990; Sigal et al., 1998; Steere et al., 1998), as well as many other potential vaccine candidates (for a detailed review, see Radolf and Samuels, 2021).

\section{Antigens based on tick targets}

In addition to bacterial antigens, proteins from the vector also represent promising vaccine candidates (de la Fuente et al., 2007b; Rego et al., 2019). Vaccines targeting tick gut or salivary gland proteins that interact with Borrelia, such as Salp15 (Anguita et al., 2002; Ramamoorthi et al., 2005; Dai et al., 2009; Sultana et al., 2016) or TROSPA (Pal et al., 2004a), could inhibit pathogen persistence in ticks and block pathogen transmission to vertebrates. Several $I$. scapularis proteins that impact borrelial persistence and transmission through ticks (Yang et al., 2014; Narasimhan et al., 2017) could be used as novel vaccination strategies. For example, a gut Dual oxidase (Duox) that supports spirochete persistence within ticks was identified as a $B$. burgdorferiinducible $I$. scapularis gene product (Yang et al., 2014). As previously demonstrated by mosquitoes that were infected with malarial parasites (Kumar et al., 2010), the supportive role of Duox in spirochete survival in ticks was attributed to its involvement in the formation of the dityrosine network, a molecular barrier surrounding the gut lumen. This network has been shown to dampen the epithelial immune response by maintaining homeostasis within the gut microbial community, while also protecting invading pathogens from the vector immune system (Kumar et al., 2010). Therefore, vector proteins like TROSPA or Duox, especially the regions that are unique to ticks, could serve as components of novel transmissionblocking Lyme disease vaccines. Additional Ixodes proteins that have been studied as potential anti-tick vaccines have also demonstrated their impacts on the acquisition or transmission of $B$. burgdorferi in ticks, including subolesin (Almazan et al., 2003; Bensaci et al., 2012), TSLPI, a tick mannose-binding lectin inhibitor (Schuijt et al., 2011), and tHRF, a tick histamine release factor (Dai et al., 2010).

Vaccination studies using a combination of tick and spirochete antigens, such as Salp15 and OspA or $\mathrm{OspC}$, were also described as markedly enhancing the protective efficacy of antibodies against $B$. burgdorferi antigens (Dai et al., 2009). A recent review highlighted the current state of knowledge about anti-tick vaccine candidates that can prevent the transmission of tick-borne pathogens (Rego et al., 2019; Bhowmick and Han, 2020).

\section{Concluding remarks}

With more than 800 tick species in existence globally, these ancient ectoparasites have evolved a remarkable tolerance to extreme climates, as well as 
survivability for prolonged periods, and the abilities to maintain and transmit varied sets of pathogens. Ixodes ticks, which arguably transmit the most diverse range of human and animal pathogens amongst all ticks, including a striking array of Lyme borreliosis agents, are remarkably adapted to engorge on a wide collection of vertebrate hosts. The interactions between a distinct set of ligand receptors contributes to the successful persistence of human pathogens, such as $B$. burgdorferi, through a complex life cycle in nature involving Ixodes ticks. Studies have established the clear evolution of an intimate relationship between the pathogen and its arthropod vector. $B$. burgdorferi can induce the expression of specific tick genes, such as TROSPA (Pal et al., 2004a), salp15 (Ramamoorthi et al., 2005; Dai et al., 2009), duox (Yang et al., 2014), and pixr (Narasimhan et al., 2017). Experimental evidence suggests that at least one of these genes, salp15, can potentially modulate host immunity in favor of the tick feeding process; therefore, $B$. burgdorferi infection may provide survival advantages to ticks. Further work is warranted to determine the exact ecological relationship between ticks and $B$. burgdorferi, particularly to ascertain whether it is parasitic or mutualistic. Studies are also needed to address the interactions between Ixodes ticks and organisms that have been identified as potential symbionts (Stewart and Bloom, 2020), as well as how polymicrobial interactions shape $B$. burgdorferi infection in ticks. The identification of additional microbial and vector gene products that are actively engaged in spirochete acquisition, maintenance, and transmission through the arthropod should also be explored in future research.

The long life span and slow post-embryonic development of Ixodes (Sauer, 1986; Sonenshine, 1993), along with the relatively limited availability of high-resolution genomic information, complicate the application of gene manipulation tools to tick research and hinder the analyses of the tick transcriptome and proteome. Future Ixodes studies are required on embryology (Sonenshine, 1993), the three-dimensional configuration of the genome (Kempfer and Pombo, 2020), gene manipulation and transgenesis (Sun et al., 2017), and paratransgenesis (Wilke and Marrelli, 2015), as these would certainly expand upon experimental opportunities and foster a deeper understanding of tick biology and development. Such efforts will also contribute to our knowledge of the molecular interactions between Borrelia and tick gene products. Specific questions to be addressed include the molecular details of how $B$. burgdorferi evades tick immunity, the gut digestive activities that occur upon spirochete arrival in feeding ticks, and the mechanism by which the pathogen continues to persist in ticks throughout the intermolt periods that are dominated by temperature extremities and starvation. Studies should also distinguish how $B$. burgdorferi crosses physical barriers, such as the chitinous gut peritrophic membrane and newly-recognized acellular barriers like the dityrosine network, and then selectively migrates through the tick gut, hemocoel, and salivary gland epithelia during transmission to mammals. Ixodes and Borrelia have probably co-evolved numerous but distinct molecular interfaces that support their coexistence.

Globally, the incidences of tick-borne diseases, including Lyme borreliosis, are increasing. At least 13 new tick-borne pathogens were recognized in the Western Hemisphere during the last 20 years (Paddock et al., 2016). It is likely that ticks evolved robust genetic and epigenetic mechanisms that promote their survival in environmental extremities and their unparalleled tolerance to a wide range of microbial pathogens. Future investigations of the genetic and epigenetic bases of tick vectorial capacity will enrich our knowledge of the interactions between Ixodes and diverse pathogens, contributing to a better understanding of tick-borne infections. In particular, more thorough knowledge about the biology of the tick- $B$. burgdorferi interaction (Kurokawa et al., 2020) not only will contribute to the development of preventive measures against Lyme disease but also serve as a paradigm for novel control measures against additional tick-borne infections.

\section{Acknowledgement}

The authors are thankful to Kathryn Nassar for assistance with the preparation of this review. We are grateful to Aravinda M. de Silva, Deborah Shroder, and Ireen Dryburgh-Barry for assistance with the preparation of the original manuscript. Lyme disease research in our laboratories is supported by several past and ongoing funding supports from the National Institutes of Health (including currently active grants, P01Al138949 and R01Al154542 to U.P), the Department of Defense, Global Lyme Alliance, Merck \& Co. Inc., the Arthritis Foundation, the American Heart Association, and the Steven and Alexandra Cohen Foundation. Erol Fikrig is an Investigator of the Howard Hughes Medical Institute. Chrysoula 
Kitsou is the recipient of the Deborah and Mark Blackman Postdoctoral Fellowship from Global Lyme Alliance.

\section{References}

Abraham, N.M., Liu, L., Jutras, B.L., Yadav, A.K., Narasimhan, S., Gopalakrishnan, V., Ansari, J.M., Jefferson, K.K., Cava, F., JacobsWagner, C., et al. (2017). Pathogen-mediated manipulation of arthropod microbiota to promote infection. Proc Natl Acad Sci U S A 114, E781E790. https://doi.org/10.1073/pnas.1613422114

Aivelo, T., Norberg, A., and Tschirren, B. (2019). Bacterial microbiota composition of Ixodes ricinus ticks: the role of environmental variation, tick characteristics and microbial interactions. PeerJ 7, e8217. https:// doi.org/10.7717/peerj.8217

Alban, P.S., Johnson, P.W., and Nelson, D.R. (2000). Serum-starvation-induced changes in protein synthesis and morphology of Borrelia burgdorferi. Microbiology 146 (Pt 1), 119-127. doi: 10.1099/00221287-146-1-119.

Alberdi, P., Mansfield, K.L., Manzano-Roman, R., Cook, C., Ayllon, N., Villar, M., Johnson, N., Fooks, A.R., and de la Fuente, J. (2016). TissueSpecific Signatures in the Transcriptional Response to Anaplasma phagocytophilum Infection of Ixodes scapularis and Ixodes ricinus Tick Cell Lines. Frontiers in cellular and infection microbiology 6, 20. https:/l doi.org/10.3389/fcimb.2016.00020

Almazan, C., Kocan, K.M., Bergman, D.K., Garcia-Garcia, J.C., Blouin, E.F., and de la Fuente, J. (2003). Identification of protective antigens for the control of Ixodes scapularis infestations using cDNA expression library immunization. Vaccine 21, 1492-1501. https://doi.org/ S0264410X02006837

Alverson, J., Bundle, S.F., Sohaskey, C.D., Lybecker, M.C., and Samuels, D.S. (2003). Transcriptional regulation of the ospAB and ospC promoters from Borrelia burgdorferi. Mol Microbiol 48, 1665-1677. doi: 10.1046/j.1365-2958.2003.03537.x

Amarasinghe, S.L., Su, S., Dong, X., Zappia, L., Ritchie, M.E., and Gouil, Q. (2020). Opportunities and challenges in long-read sequencing data analysis. Genome Biol 21, 30. https://doi.org/10.1186/ s13059-020-1935-5

Anderson, J.F. (1989). Epizootiology of Borrelia in Ixodes tick vectors and reservoir hosts. Rev Infect Dis 11 Suppl 6, S1451-1459. doi: 10.1093/ clinids/11.supplement_6.s1451.

Anderson, J.F., Duray, P.H., and Magnarelli, L.A. (1987). Prevalence of Borrelia burgdorferi in white-footed mice and Ixodes dammini at Fort McCoy, Wis. J Clin Microbiol 25, 1495-1497. doi: 10.1128/JCM. 25.8.1495-1497.1987.

Anguita, J., Hedrick, M.N., and Fikrig, E. (2003). Adaptation of Borrelia burgdorferi in the tick and the mammalian host. FEMS Microbiol Rev 27, 493-504. doi: 10.1016/S0168-6445(03)00036-6.

Anguita, J., Ramamoorthi, N., Das, S., Conze, D., Askenase, P., Rincón, M., Kantor, F.S., and Fikrig, E. (2002). Salp15, an Ixodes scapularis saliva protein, inhibits CD4+ T cell activation. Immunity 16, 849-859. doi: 10.1016/s1074-7613(02)00325-4.

Arnold, W.K., Savage, C.R., Brissette, C.A., Seshu, J., Livny, J., and Stevenson, B. (2016). RNA-Seq of Borrelia burgdorferi in Multiple Phases of Growth Reveals Insights into the Dynamics of Gene Expression, Transcriptome Architecture, and Noncoding RNAs. PLOS One 11, e0164165. https://doi.org/10.1371/journal.pone.0164165

Arnold, W.K., Savage, C.R., Lethbridge, K.G., Smith, T.C., 2nd, Brissette, C.A., Seshu, J., and Stevenson, B. (2018). Transcriptomic insights on the virulence-controlling $\mathrm{Csr} A, \mathrm{BadR}, \mathrm{RpoN}$, and RpoS regulatory networks in the Lyme disease spirochete. PLoS One 13, e0203286. https://doi.org/10.1371/journal.pone.0203286

Aucott, J.N., Crowder, L.A., and Kortte, K.B. (2013). Development of a foundation for a case definition of post-treatment Lyme disease syndrome. International journal of infectious diseases : IJID : 17, e443-449. https://doi.org/10.1016/j.jij. 2013.01.008

Beerntsen, B.T., James, A.A., and Christensen, B.M. (2000). Genetics of mosquito vector competence. Microbiol Mol Biol Rev 64, 115-137. doi: 10.1128/mmbr.64.1.115-137.2000.

Benach, J.L., Bosler, E.M., and Hanrahan, J.P. (1983). Spirochetes isolated from the blood of two patients with Lyme disease. $\mathrm{N} \mathrm{Engl} \mathrm{J}$ Med 308, 740-742.

Bensaci, M., Bhattacharya, D., Clark, R., and Hu, H.T. (2012). Oral Vaccination With Vaccinia Virus Expressing the Tick Antigen Subolesin Inhibits Tick Feeding and Transmission of Borrelia burgdorferi Vaccination. Vaccine 30(42):6040-6. doi: 10.1016/j.vaccine. 2012.07.053.

Bernard, Q., Smith, A.A., Yang, X., Koci, J., Foor, S.D., Cramer, S.D., Zhuang, X., Dwyer, J.E., Lin, Y.P., Mongodin, E.F., et al. (2018). Plasticity in early immune evasion strategies of a bacterial pathogen. Proc Natl Acad Sci U S A. https://doi.org/10.1073/pnas.1718595115

Bhowmick, B., and Han, Q. (2020). Understanding Tick Biology and Its Implications in Anti-tick and Transmission Blocking Vaccines Against Tick-Borne Pathogens. Front Vet Sci 7, 319. https://doi.org/10.3389/ fvets. 2020.00319

Bonev, B., Mendelson Cohen, N., Szabo, Q., Fritsch, L., Papadopoulos, G.L., Lubling, Y., Xu, X., Lv, X., Hugnot, J.P., Tanay, A., et al. (2017) Multiscale 3D Genome Rewiring during Mouse Neural Development. Cell 171, 557-572 e524. https://doi.org/10.1016/j.cell.2017.09.043

Bonnet, S.I., Binetruy, F., Hernandez-Jarguin, A.M., and Duron, O. (2017). The Tick Microbiome: Why Non-pathogenic Microorganisms Matter in Tick Biology and Pathogen Transmission. Frontiers in cellular and infection microbiology 7, 236. https://doi.org/10.3389/fcimb.2017.00236

Bontemps-Gallo, S., Lawrence, K.A., Richards, C.L., and Gherardini, F.C. (2018). Borrelia burgdorferi genes, bb0639-0642, encode a putative putrescine/spermidine transport system, PotABCD, that is spermidine specific and essential for cell survival. Mol Microbiol 108, 350-360. https://doi.org/10.1111/mmi.13940

Boyer, L., Magoc, L., Dejardin, S., Cappillino, M., Paquette, N., Hinault, C., Charriere, G.M., Ip, W.K., Fracchia, S., Hennessy, E., et al. (2011) Pathogen-derived effectors trigger protective immunity via activation of the Rac2 enzyme and the IMD or Rip kinase signaling pathway. Immunity 35, 536-549. https://doi.org/10.1016/j.immuni.2011.08.015

Boyle, W.K., Groshong, A.M., Drecktrah, D., Boylan, J.A., Gherardini, F.C., Blevins, J.S., Samuels, D.S., and Bourret, T.J. (2019). DksA Controls the Response of the Lyme Disease Spirochete Borrelia burgdorferi to Starvation. J Bacteriol 201. https://doi.org/10.1128/JB.00582-18

Boyle, W.K., Wilder, H.K., Lawrence, A.M., and Lopez, J.E. (2014). Transmission dynamics of Borrelia turicatae from the arthropod vector PLoS Negl Trop Dis 8, e2767. https://doi.org/10.1371/journal.pntd. 0002767

Brangulis, K., Akopjana, I., Petrovskis, I., Kazaks, A., Jekabsons, A., Jaudzems, K., Viksna, A.,

Bertins, M., and Tars, K. (2020a). Structural analysis of Borrelia burgdorferi periplasmic lipoprotein BB0365 involved in Lyme disease infection. FEBS Lett 594, 317-326. https://doi.org/10.1002/1873-3468. 13594

Brangulis, K., Akopjana, I., Petrovskis, I., Kazaks, A., Zelencova, D. Jekabsons, A., Jaudzems, K., and Tars, K. (2020b). BBE31 from the Lyme disease agent Borrelia burgdorferi, known to play an important role in successful colonization of the mammalian host, shows the ability to bind glutathione. Biochim Biophys Acta Gen Subj 1864, 129499. https://doi.org/10.1016/.jbbagen.2019.129499

Brisson, D., Drecktrah, D., Eggers, C.H., and Samuels, D.S. (2012). Genetics of Borrelia burgdorferi. Annual review of genetics 46, 515-536. https://doi.org/10.1146/annurev-genet-011112-112140

Broadwater, A.H., Sonenshine, D.E., Hynes, W.L., Ceraul, S., and De, S.A. (2002). Glass capillary tube feeding: a method for infecting nymphal Ixodes scapularis (Acari: Ixodidae) with the Lyme disease 
spirochete Borrelia burgdorferi. J Med Entomol 39, 285-292. doi: 10.1603/0022-2585-39.2.285.

Brooks, C.S., Hefty, P.S., Jolliff, S.E., and Akins, D.R. (2003). Global analysis of Borrelia burgdorferi genes regulated by mammalian hostspecific signals. Infect Immun 71, 3371-3383. doi: 10.1128/iai. 71.6.3371-3383.2003.

Brorson, O., and Brorson, S.H. (1998). In vitro conversion of Borrelia burgdorferi to cystic forms in spinal fluid, and transformation to mobile spirochetes by incubation in BSK-H medium. Infection 26, 144-150. doi: 10.1007/BF02771839.

Brorson, O., and Brorson, S.H. (2004). An in vitro study of the susceptibility of mobile and cystic forms of Borrelia burgdorferi to tinidazole. Int Microbiol 7, 139-142.

Bucher, G., Scholten, J., and Klingler, M. (2002). Parental RNAi in Tribolium (Coleoptera). Curr Biol 12, R85-86. doi: 10.1016/ s0960-9822(02)00666-8.

Buchon, N., Broderick, N.A., and Lemaitre, B. (2013). Gut homeostasis in a microbial world: insights from Drosophila melanogaster. Nat Rev Microbiol 11, 615-626. https://doi.org/10.1038/nrmicro3074

Buckles, E.L., Earnhart, C.G., and Marconi, R.T. (2006). Analysis of antibody response in humans to the type $\mathrm{A}$ OspC loop 5 domain and assessment of the potential utility of the loop 5 epitope in Lyme disease vaccine development. Clin Vaccine Immunol 13, 1162-1165. doi: 10.1128/CVI.00099-06.

Bugrysheva, J.V., Bryksin, A.V., Godfrey, H.P., and Cabello, F.C. (2005). Borrelia burgdorferi rel is responsible for generation of guanosine-3'diphosphate-5'-triphosphate and growth control. Infect Immun 73, 4972-4981. doi: 10.1128/IAl.73.8.4972-4981.2005

Bugrysheva, J.V., Pappas, C.J., Terekhova, D.A., lyer, R., Godfrey, H.P., Schwartz, I., and Cabello, F.C. (2015). Characterization of the RelBbu Regulon in Borrelia burgdorferi Reveals Modulation of Glycerol Metabolism by (p)ppGpp. PLoS One 10, e0118063. https://doi.org/ 10.1371/journal.pone. 0118063

Burgdorfer, W., Hayes, S., and Benach, J. (1988). Development of Borrelia burgdorferi in ixodid tick vectors. Ann NY Acad Sci 539, 172-179. doi: 10.1111/j.1749-6632.1988.tb31851.x.

Bykowski, T., Woodman, M.E., Cooley, A.E., Brissette, C.A., Brade, V., Wallich, R., Kraiczy, P., and Stevenson, B. (2007a). Coordinated expression of Borrelia burgdorferi complement regulator-acquiring surface proteins during the Lyme disease spirochete's mammal-tick infection cycle. Infect Immun 75, 4227-4236. doi: 10.1128/IAI.00604-07

Bykowski, T., Woodman, M.E., Cooley, A.E., Brissette, C.A., Wallich, R., Brade, V., Kraiczy, P., and Stevenson, B. (2007b). Borrelia burgdorferi complement regulator-acquiring surface proteins (BbCRASPs): Expression patterns during the mammal-tick infection cycle. Int J Med Microbiol. 298 Suppl 1(Suppl 1):249-56. doi: 10.1016/j.jjmm. 2007.10.002

Cabezas-Cruz, A., Espinosa, P., Alberdi, P., and de la Fuente, J. (2019). Tick-Pathogen Interactions: The Metabolic Perspective. Trends Parasitol 35, 316-328. https://doi.org/10.1016/j.pt.2019.01.006

Caimano, M.J., Drecktrah, D., Kung, F., and Samuels, D.S. (2016). Interaction of the Lyme disease spirochete with its tick vector. Cell Microbiol 18, 919-927. https://doi.org/10.1111/cmi.12609

Caimano, M.J., Dunham-Ems, S., Allard, A.M., Cassera, M.B., Kenedy, M., and Radolf, J.D. (2015). Cyclic di-GMP modulates gene expression in Lyme disease spirochetes at the tick-mammal interface to promote spirochete survival during the blood meal and tick-to-mammal transmission. Infect Immun 83, 3043-3060. https://doi.org/10.1128/IAl. 00315-15

Caimano, M.J., Eggers, C.H., Gonzalez, C.A., and Radolf, J.D. (2005). Alternate sigma factor RpoS is required for the in vivo-specific repression of Borrelia burgdorferi plasmid Ip54-borne ospA and Ip6.6 genes. J Bacteriol 187, 7845-7852. doi: 10.1128/JB. 187.22.7845-7852.2005.
Caimano, M.J., Eggers, C.H., Hazlett, K.R., and Radolf, J.D. (2004). RpoS is not central to the general stress response in Borrelia burgdorferi but does control expression of one or more essential virulence determinants. Infect Immun 72, 6433-6445. doi: 10.1128/IAI. 72.11.6433-6445.2004.

Caimano, M.J., Groshong, A.M., Belperron, A., Mao, J., Hawley, K.L., Luthra, A., Graham, D.E., Earnhart, C.G., Marconi, R.T., Bockenstedt, L.K., et al. (2019). The RpoS Gatekeeper in Borrelia burgdorferi: An Invariant Regulatory Scheme That Promotes Spirochete Persistence in Reservoir Hosts and Niche Diversity. Front Microbiol 10, 1923. https:/l doi.org/10.3389/fmicb.2019.01923

Caimano, M.J., Iyer, R., Eggers, C.H., Gonzalez, C., Morton, E.A., Gilbert, M.A., Schwartz, I., and Radolf, J.D. (2007). Analysis of the RpoS regulon in Borrelia burgdorferi in response to mammalian host signals provides insight into RpoS function during the enzootic cycle. Mol Microbiol 65, 1193-1217. doi: 10.1111/j.1365-2958.2007.05860.x.

Caine, J.A., Lin, Y.P., Kessler, J.R., Sato, H., Leong, J.M., and Coburn, J. (2017). Borrelia burgdorferi outer surface protein C (OspC) binds complement component $\mathrm{C} 4 \mathrm{~b}$ and confers bloodstream survival. Cell Microbiol 19. https://doi.org/10.1111/cmi.12786

Carrasco, S.E., Troxell, B., Yang, Y., Brandt, S.L., Li, H., Sandusky, G.E., Condon, K.W., Serezani, C.H., and Yang, X.F. (2015). Outer surface protein OspC is an antiphagocytic factor that protects Borrelia burgdorferi from phagocytosis by macrophages. Infect Immun 83, 4848-4860. https://doi.org/10.1128//AI.01215-15

Casjens, S., Palmer, N., van Vugt, R., Huang, W.M., Stevenson, B., Rosa, P., Lathigra, R., Sutton, G., Peterson, J., Dodson, R.J., et al. (2000). A bacterial genome in flux: the twelve linear and nine circular extrachromosomal DNAs in an infectious isolate of the Lyme disease spirochete Borrelia burgdorferi. Mol Microbiol 35, 490-516. doi: 10.1046/j.1365-2958.2000.01698.x.

Casjens, S.R., Mongodin, E.F., Qiu, W.G., Dunn, J.J., Luft, B.J., FraserLiggett, C.M., and Schutzer, S.E. (2011). Whole-genome sequences of two Borrelia afzelii and two Borrelia garinii Lyme disease agent isolates. J Bacteriol 193, 6995-6996. https://doi.org/193/24/6995

Casjens, S.R., Mongodin, E.F., Qiu, W.G., Luft, B.J., Schutzer, S.E., Gilcrease, E.B., Huang, W.M., Vujadinovic, M., Aron, J.K., Vargas, L.C., et al. (2012). Genome stability of Lyme disease spirochetes: comparative genomics of Borrelia burgdorferi plasmids. PLOS ONE 7 e33280. https://doi.org/10.1371/journal.pone. 0033280

Catteruccia, F. (2007). Malaria vector control in the third millennium: progress and perspectives of molecular approaches. Pest Manag Sci 63, 634-640. doi: $10.1002 / p s .1$

Catteruccia, F., Nolan, T., Loukeris, T.G., Blass, C., Savakis, C., Kafatos, F.C., and Crisanti, A. (2000). Stable germline transformation of the malaria mosquito Anopheles stephensi. Nature 405, 959-962. doi: 10.1038/35016096.

Charrier, N.P., Couton, M., Voordouw, M.J., Rais, O., Durand-Hermouet, A., Hervet, C., Plantard, O., and Rispe, C. (2018). Whole body transcriptomes and new insights into the biology of the tick Ixodes ricinus. Parasites \& vectors 11,364 . https://doi.org/10.1186/ s13071-018-2932-3

Chavez, A.S.O., O'Neal, A.J., Santambrogio, L., Kotsyfakis, M., and Pedra, J.H.F. (2019). Message in a vesicle - trans-kingdom intercommunication at the vector-host interface. Journal of cell science 132. https://doi.org/10.1242/jcs.224212

Chen, T., Xiang, X., Xu, H., Zhang, X., Zhou, B., Yang, Y., Lou, Y., and Yang, X.F. (2018). LtpA, a CdnL-type CarD regulator, is important for the enzootic cycle of the Lyme disease pathogen. Emerg Microbes Infect 7, 126. https://doi.org/10.1038/s41426-018-0122-1

Chou, S., Daugherty, M.D., Peterson, S.B., Biboy, J., Yang, Y., Jutras, B.L., Fritz-Laylin, L.K., Ferrin, M.A., Harding, B.N., Jacobs-Wagner, C., et al. (2015). Transferred interbacterial antagonism genes augment eukaryotic innate immune function. Nature 518, 98-101. https://doi.org/ 10.1038 /nature 13965 
Chrudimska, T., Slaninova, J., Rudenko, N., Ruzek, D., and Grubhoffer, L. (2011). Functional characterization of two defensin isoforms of the hard tick Ixodes ricinus. Parasites \& vectors 4, 63. https://doi.org/ 10.1186/1756-3305-4-63

Clayton, A.M., Dong, Y., and Dimopoulos, G. (2014). The Anopheles innate immune system in the defense against malaria infection. J Innate Immun 6, 169-181. https://doi.org/10.1159/000353602

Coburn, J., and Cugini, C. (2003). Targeted mutation of the outer membrane protein P66 disrupts attachment of the Lyme disease agent, Borrelia burgdorferi, to integrin alpha-v-beta-3. Proc Natl Acad Sci U S A 100, 7301-7306. doi: 10.1073/pnas. 1131117100

Coleman, J.L., Gebbia, J.A., Piesman, J., Degen, J.L., Bugge, T.H., and Benach, J.L. (1997). Plasminogen is required for efficient dissemination of Borrelia burgdorferi in ticks and for enhancement of spirochetemia in mice. Cell 89, 1111-1119. doi: 10.1016/s0092-8674(00)80298-6.

Coleman, J.L., Sellati, T.J., Testa, J.E., Kew, R.R., Furie, M.B., and Benach, J.L. (1995). Borrelia burgdorferi binds plasminogen, resulting in enhanced penetration of endothelial monolayers. Infect Immun 63, 2478-2484. doi: 10.1128/IAl.63.7.2478-2484.1995.

Concepcion, M.B., and Nelson, D.R. (2003). Expression of spoT in Borrelia burgdorferi during serum starvation. J Bacteriol 185, 444-452. https://doi.org/10.1128/jb.185.2.444-452.2003

Contreras, M., Villar, M., Alberdi, P., and de la Fuente, J. (2016). Vaccinomics Approach to Tick Vaccine Development. Methods Mol Biol 1404, 275-286. https://doi.org/10.1007/978-1-4939-3389-1_19

Contreras, M., Villar, M., and de la Fuente, J. (2019). A Vaccinomics Approach for the Identification of Tick Protective Antigens for the Control of Ixodes ricinus and Dermacentor reticulatus Infestations in Companion Animals. Front Physiol 10, 977. https://doi.org/10.3389/ fphys.2019.00977

Cotte, V., Sabatier, L., Schnell, G., Carmi-Leroy, A., Rousselle, J.C., Arsene-Ploetze, F., Malandrin, L., Sertour, N., Namane, A., Ferquel, E., et al. (2014). Differential expression of Ixodes ricinus salivary gland proteins in the presence of the Borrelia burgdorferi sensu lato complex. J Proteomics 96, 29-43. https://doi.org/10.1016/j.jprot.2013.10.033

Coumou, J., Narasimhan, S., Trentelman, J.J., Wagemakers, A., Koetsveld, J., Ersoz, J.I., Oei, A., Fikrig, E., and Hovius, J.W. (2016). Ixodes scapularis dystroglycan-like protein promotes Borrelia burgdorferi migration from the gut. J Mol Med (Berl) 94, 361-370. https://doi.org/10.1007/s00109-015-1365-0

Coumou, J., Wagemakers, A., Narasimhan, S., Schuijt, T.J., Ersoz, J.I., Oei, A., de Boer, O.J., Roelofs, J., Fikrig, E., and Hovius, J.W. (2019). The role of Mannose Binding Lectin in the immune response against Borrelia burgdorferi sensu lato. Scientific reports 9, 1431. https://doi.org/ 10.1038/s41598-018-37922-8

Couper, L., and Swei, A. (2018). Tick Microbiome Characterization by Next-Generation 16S rRNA Amplicon Sequencing. J Vis Exp. https:/l doi.org/10.3791/58239

Cui, H., Tsuda, K., and Parker, J.E. (2015). Effector-triggered immunity: from pathogen perception to robust defense. Annu Rev Plant Biol 66, 487-511. https://doi.org/10.1146/annurev-arplant-050213-040012

Dai, J., Narasimhan, S., Zhang, L., Liu, L., Wang, P., and Fikrig, E. (2010). Tick histamine release factor is critical for Ixodes scapularis engorgement and transmission of the lyme disease agent. PLoS Pathog 6, e1001205. https://doi.org/10.1371/journal.ppat.1001205

Dai, J., Wang, P., Adusumilli, S., Booth, C.J., Narasimhan, S., Anguita, J., and Fikrig, E. (2009). Antibodies against a tick protein, Salp15, protect mice from the Lyme disease agent. Cell Host Microbe 6, 482-492. https://doi.org/S1931-3128(09)00348-5 [pii]10.1016/j.chom.2009.10.006

Dale, C., and Moran, N.A. (2006). Molecular interactions between bacterial symbionts and their hosts. Cell 126, 453-465. doi: 10.1016/ j.cell.2006.07.014.

Das, S., Banerjee, G., DePonte, K., Marcantonio, N., Kantor, F.S., and Fikrig, E. (2001). Salp25D, an Ixodes scapularis antioxidant, is 1 of 14 immunodominant antigens in engorged tick salivary glands. J Infect Dis 184, 1056-1064. doi: 10.1086/323351.

Das, S., Marcantonio, N., Deponte, K., Telford, S.R., 3rd, Anderson, J.F., Kantor, F.S., and Fikrig, E. (2000). SALP16, a gene induced in Ixodes scapularis salivary glands during tick feeding. Am J Trop Med Hyg 62, 99-105. doi: 10.4269/aitmh.2000.62.99.

de la Fuente, J., Antunes, S., Bonnet, S., Cabezas-Cruz, A., Domingos, A.G., Estrada-Pena, A., Johnson, N., Kocan, K.M., Mansfield, K.L., Nijhof, A.M., et al. (2017). Tick-Pathogen Interactions and Vector Competence: Identification of Molecular Drivers for Tick-Borne Diseases. Frontiers in cellular and infection microbiology 7, 114. https:// doi.org/10.3389/fcimb.2017.00114

de la Fuente, J., Kocan, K.M., Almazan, C., and Blouin, E.F. (2007a). RNA interference for the study and genetic manipulation of ticks. Trends Parasitol 23, 427-433. doi: 10.1016/j.pt.2007.07.002.

de la Fuente, J., Kocan, K.M., and Blouin, E.F. (2007b). Tick vaccines and the transmission of tick-borne pathogens. Vet Res Commun 31 Suppl 1 , $85-90$

de la Fuente, J., Waterhouse, R.M., Sonenshine, D.E., Roe, R.M., Ribeiro, J.M., Sattelle, D.B., and Hill, C.A. (2016). Tick Genome Assembled: New Opportunities for Research on Tick-Host-Pathogen Interactions. Frontiers in cellular and infection microbiology 6, 103. https://doi.org/ 10.3389/fcimb.2016.00103

de Silva, A.M. (2016). Ticks Take Cues from Mammalian Interferon. Cell Host Microbe 20, 3-4. https://doi.org/10.1016/j.chom.2016.06.016

de Silva, A.M., and Fikrig, E. (1995). Growth and migration of Borrelia burgdorferi in Ixodes ticks during blood feeding. Am J Trop Med Hyg 53, 397-404. doi: 10.4269/ajtmh.1995.53.397.

de Silva, A.M., and Fikrig, E. (1997). Arthropod- and host-specific gene expression by Borrelia burgdorferi. J Clin Invest 99, 377-379. doi: 10.1172/JCl119169.

de Silva, A.M., Telford, S.R., Brunet, L.R., Barthold, S.W., and Fikrig, E. (1996). Borrelia burgdorferi OspA is an arthropod-specific transmissionblocking Lyme disease vaccine. J Exp Med 183, 271-275. doi: 10.1084/ jem.183.1.271.

Di Venere, M., Fumagalli, M., Cafiso, A., De Marco, L., Epis, S., Plantard, O., Bardoni, A., Salvini, R., Viglio, S., Bazzocchi, C., et al. (2015). Ixodes ricinus and Its Endosymbiont Midichloria mitochondrii: $A$ Comparative Proteomic Analysis of Salivary Glands and Ovaries. PLoS One 10, e0138842. https://doi.org/10.1371/journal.pone. 0138842

Ding, J., Adiconis, X., Simmons, S.K., Kowalczyk, M.S., Hession, C.C., Marjanovic, N.D., Hughes, T.K., Wadsworth, M.H., Burks, T., Nguyen, L.T., et al. (2020). Systematic comparison of single-cell and singlenucleus RNA-sequencing methods. Nat Biotechnol 38, 737-746. https:// doi.org/10.1038/s41587-020-0465-8

Drecktrah, D., Hall, L.S., Brinkworth, A.J., Comstock, J.R., Wassarman, K.M., and Samuels, D.S. (2020). Characterization of 6S RNA in the Lyme disease spirochete. Mol Microbiol 113, 399-417. https://doi.org/ $10.1111 / \mathrm{mmi} .14427$

Drecktrah, D., Hall, L.S., Rescheneder, P., Lybecker, M., and Samuels, D.S. (2018). The Stringent Response-Regulated sRNA Transcriptome of Borrelia burgdorferi. Frontiers in cellular and infection microbiology 8, 231. https://doi.org/10.3389/fcimb.2018.00231

Drecktrah, D., Lybecker, M., Popitsch, N., Rescheneder, P., Hall, L.S., and Samuels, D.S. (2015). The Borrelia burgdorferi RelA/SpoT Homolog and Stringent Response Regulate Survival in the Tick Vector and Global Gene Expression during Starvation. PLoS Pathog 11, e1005160. https://doi.org/10.1371/journal.ppat.1005160

Dudchenko, O., Batra, S.S., Omer, A.D., Nyquist, S.K., Hoeger, M., Durand, N.C., Shamim, M.S., Machol, I., Lander, E.S., Aiden, A.P., et al. (2017). De novo assembly of the Aedes aegypti genome using $\mathrm{Hi}-\mathrm{C}$ yields chromosome-length scaffolds. Science 356, 92-95. https:// doi.org/10.1126/science.aal3327

Dunham-Ems, S.M., Caimano, M.J., Eggers, C.H., and Radolf, J.D. (2012). Borrelia burgdorferi requires the alternative sigma factor RpoS 
for dissemination within the vector during tick-to-mammal transmission. PLoS Pathog 8, e1002532. https://doi.org/10.1371/journal.ppat. 1002532

Dunham-Ems, S.M., Caimano, M.J., Pal, U., Wolgemuth, C.W., Eggers, C.H., Balic, A., and Radolf, J.D. (2009). Live imaging reveals a biphasic mode of dissemination of Borrelia burgdorferi within ticks. J Clin Invest 119, 3652-3665. https://doi.org/39401

Duray, P.H., Yin, S.R., Ito, Y., Bezrukov, L., Cox, C., Cho, M.S., Fitzgerald, W., Dorward, D., Zimmerberg, J., and Margolis, L. (2005). Invasion of human tissue ex vivo by Borrelia burgdorferi. J Infect Dis 191, 1747-1754.

Earnhart, C.G., Buckles, E.L., and Marconi, R.T. (2007). Development of an OspC-based tetravalent, recombinant, chimeric vaccinogen that elicits bactericidal antibody against diverse Lyme disease spirochete strains. Vaccine 25, 466-480. doi: 10.1016/j.vaccine.2006.07.052.

Earnhart, C.G., and Marconi, R.T. (2007a). An octavalent lyme disease vaccine induces antibodies that recognize all incorporated OspC typespecific sequences. Hum Vaccin 3, 281-289. doi: 10.4161/hv.4661.

Earnhart, C.G., and Marconi, R.T. (2007b). OspC phylogenetic analyses support the feasibility of a broadly protective polyvalent chimeric Lyme disease vaccine. Clin Vaccine Immunol 14, 628-634. doi: 10.1128/CVI. 00409-06.

Estrada-Pena, A., Cabezas-Cruz, A., and Obregon, D. (2020). Resistance of Tick Gut Microbiome to Anti-Tick Vaccines, Pathogen Infection and Antimicrobial Peptides. Pathogens 9. https://doi.org/10.3390/ pathogens 9040309

Fazzino, L., Tilly, K., Dulebohn, D.P., and Rosa, P.A. (2015). Long-term survival of Borrelia burgdorferi lacking the hibernation promotion factor homolog in the unfed tick vector. Infect Immun 83, 4800-4810. https:// doi.org/10.1128/IAl.00925-15

Ferrandon, D., Imler, J.L., Hetru, C., and Hoffmann, J.A. (2007). The Drosophila systemic immune response: sensing and signalling during bacterial and fungal infections. Nature reviews Immunology 7, 862-874. https://doi.org/10.1038/nri2194

Figlerowicz, M., Urbanowicz, A., Lewandowski, D., Jodynis-Liebert, J., and Sadowski, C. (2013). Functional insights into recombinant TROSPA protein from Ixodes ricinus. PLoS One 8, e76848. https://doi.org/ 10.1371/journal.pone.0076848

Fikrig, E., Barthold, S.W., Kantor, F.S., and Flavell, R.A. (1990). Protection of mice against the Lyme disease agent by immunizing with recombinant OspA. Science 250, 553-556. doi: 10.1126/science. 2237407

Fikrig, E., and Narasimhan, S. (2006). Borrelia burgdorferi--traveling incognito? Microbes Infect 8, 1390-1399. https://doi.org/ S1286-4579(06)00046-3 [pii] 10.1016/j.micinf.2005.12.022

Fikrig, E., Pal, U., Chen, M., Anderson, J.F., and Flavell, R.A. (2004). OspB antibody prevents Borrelia burgdorferi colonization of Ixodes scapularis. Infect Immun 72, 1755-1759.

Fingerle, V., Goettner, G., Gern, L., Wilske, B., and Schulte-Spechtel, U. (2007). Complementation of a Borrelia afzelii OspC mutant highlights the crucial role of OspC for dissemination of Borrelia afzelii in Ixodes ricinus. Int J Med Microbiol 297, 97-107. doi: 10.1016/j.jmm. 2006.11.003

Finlay, B.B., and Cossart, P. (1997). Exploitation of mammalian host cell functions by bacterial pathogens. Science $276,718-725$. doi: $10.1126 /$ science.276.5313.718

Fisher, M.A., Grimm, D., Henion, A.K., Elias, A.F., Stewart, P.E., Rosa, P.A., and Gherardini, F.C. (2005). Borrelia burgdorferi sigma54 is required for mammalian infection and vector transmission but not for tick colonization. Proc Natl Acad Sci U S A 102, 5162-5167. https:/l doi.org/0408536102 [pii] 10.1073/pnas.0408536102

Floden, A.M., Watt, J.A., and Brissette, C.A. (2011). Borrelia burgdorferi enolase is a surface-exposed plasminogen binding protein. PLOS ONE 6, e27502. https://doi.org/10.1371/journal.pone.0027502 PONED-11-11262 [pii]
Fogaca, A.C., da Silva, P.I., Jr., Miranda, M.T., Bianchi, A.G., Miranda, A., Ribolla, P.E., and Daffre, S. (1999). Antimicrobial activity of a bovine hemoglobin fragment in the tick Boophilus microplus. J Biol Chem 274, 25330-25334. doi: 10.1074/jbc.274.36.25330.

Francischetti, I.M., My Pham, V., Mans, B.J., Andersen, J.F., Mather, T.N., Lane, R.S., and Ribeiro, J.M. (2005). The transcriptome of the salivary glands of the female western black-legged tick Ixodes pacificus (Acari: Ixodidae). Insect Biochem Mol Biol 35, 1142-1161. doi: 10.1016/j.ibmb. 2005.05.007.

Fraser, C.M., Casjens, S., Huang, W.M., Sutton, G.G., Clayton, R., Lathigra, R., White, O., Ketchum, K.A., Dodson, R., Hickey, E.K., et al. (1997). Genomic sequence of a Lyme disease spirochaete, Borrelia burgdorferi. Nature 390, 580-586. doi: 10.1038/37551.

Freedman, J.C., Rogers, E.A., Kostick, J.L., Zhang, H., Iyer, R., Schwartz, I., and Marconi, R.T. (2010). Identification and molecular characterization of a cyclic-di-GMP effector protein, PlzA (BB0733): additional evidence for the existence of a functional cyclic-di-GMP regulatory network in the Lyme disease spirochete, Borrelia burgdorferi. FEMS Immunol Med Microbiol 58, 285-294. https://doi.org/FIM635

Fuchs, H., Wallich, R., Simon, M.M., and Kramer, M.D. (1994). The outer surface protein $\mathrm{A}$ of the spirochete Borrelia burgdorferi is a plasmin(ogen) receptor. Proc Natl Acad Sci (U S A) 91, 12594-12598. doi: 10.1073/pnas.91.26.12594.

Fung, B.P., McHugh, G.L., Leong, J.M., and Steere, A.C. (1994). Humoral immune response to outer surface protein $\mathrm{C}$ of Borrelia burgdorferi in Lyme disease: role of the immunoglobulin $\mathrm{M}$ response in the serodiagnosis of early infection. Infect Immun 62, 3213-3221. doi: 10.1128/IAl.62.8.3213-3221.

Ganz, T. (2003). Defensins: antimicrobial peptides of innate immunity. Nature reviews Immunology 3, 710-720. https://doi.org/10.1038/nri1180

Geraci, N.S., Spencer Johnston, J., Paul Robinson, J., Wikel, S.K., and Hill, C.A. (2007). Variation in genome size of argasid and ixodid ticks. Insect Biochem Mol Biol 37, 399-408. doi: 10.1016/j.ibmb.2006.12.007.

Gilbert, M.A., Morton, E.A., Bundle, S.F., and Samuels, D.S. (2007). Artificial regulation of ospC expression in Borrelia burgdorferi. Mol Microbiol 63, 1259-1273. doi: 10.1111/j.1365-2958.2007.05593.x.

Gold, B., Deng, H., Bryk, R., Vargas, D., Eliezer, D., Roberts, J., Jiang, X., and Nathan, C. (2008). Identification of a copper-binding metallothionein in pathogenic mycobacteria. Nat Chem Biol 4, 609-616. https://doi.org/10.1038/nchembio.109

Gomes-Solecki, M., Arnaboldi, P.M., Backenson, P.B., Benach, J.L., Cooper, C.L., Dattwyler, R.J., Diuk-Wasser, M., Fikrig, E., Hovius, J.W., Laegreid, W., et al. (2020). Protective Immunity and New Vaccines for Lyme Disease. Clin Infect Dis 70, 1768-1773. https://doi.org/10.1093/ $\mathrm{cid} / \mathrm{ciz} 872$

Grabowski, J.M., Perera, R., Roumani, A.M., Hedrick, V.E., Inerowicz, H.D., Hill, C.A., and Kuhn, R.J. (2016). Changes in the Proteome of Langat-Infected Ixodes scapularis ISE6 Cells: Metabolic Pathways Associated with Flavivirus Infection. PLoS Negl Trop Dis 10, e0004180. https://doi.org/10.1371/journal.pntd.0004180

Greay, T.L., Gofton, A.W., Paparini, A., Ryan, U.M., Oskam, C.L., and Irwin, P.J. (2018). Recent insights into the tick microbiome gained through next-generation sequencing. Parasites \& vectors 11,12 . https:// doi.org/10.1186/s13071-017-2550-5

Grewe, C., and Nuske, J.H. (1996). Immunolocalization of a $22 \mathrm{kDa}$ protein (IPLA7, P22) of Borrelia burgdorferi. FEMS Microbiol Lett 138, 215-219. doi: 10.1111/j.1574-6968.1996.tb08160.x.

Grimm, D., Eggers, C.H., Caimano, M.J., Tilly, K., Stewart, P.E., Elias, A.F., Radolf, J.D., and Rosa, P.A. (2004a). Experimental assessment of the roles of linear plasmids Ip25 and Ip28-1 of Borrelia burgdorferi throughout the infectious cycle. Infect Immun 72, 5938-5946.

Grimm, D., Tilly, K., Bueschel, D.M., Fisher, M.A., Policastro, P.F., Gherardini, F.C., Schwan, T.G., and Rosa, P.A. (2005). Defining plasmids required by Borrelia burgdorferi for colonization of tick vector 
Ixodes scapularis (Acari: Ixodidae). J Med Entomol 42, 676-684. doi: 10.1128/AAI.72.10.5938-5946.2004.

Grimm, D., Tilly, K., Byram, R., Stewart, P.E., Krum, J.G., Bueschel, D.M., Schwan, T.G., Policastro, P.F., Elias, A.F., and Rosa, P.A. (2004b). Outer-surface protein $C$ of the Lyme disease spirochete: a protein induced in ticks for infection of mammals. Proc Natl Acad Sci U S A 101, 3142-3147. doi: 10.1073/pnas.0306845101.

Groshong, A.M., Dey, A., Bezsonova, I., Caimano, M.J., and Radolf, J.D. (2017). Peptide Uptake Is Essential for Borrelia burgdorferi Viability and Involves Structural and Regulatory Complexity of its Oligopeptide Transporter. mBio 8. https://doi.org/10.1128/mBio.02047-17

Grubhoffer, L., Golovchenko, M., Vancova, M., Zacharovova-Slavickova, K., Rudenko, N., and Oliver, J.H., Jr. (2005). Lyme borreliosis: insights into tick-/host-borrelia relations. Folia parasitologica 52, 279-294. doi: 10.14411/fp.2005.039.

Gulia-Nuss, M., Nuss, A.B., Meyer, J.M., Sonenshine, D.E., Roe, R.M., Waterhouse, R.M., Sattelle, D.B., de la Fuente, J., Ribeiro, J.M., Megy, K., et al. (2016). Genomic insights into the Ixodes scapularis tick vector of Lyme disease. Nat Commun 7, 10507. https://doi.org/10.1038/ ncomms 10507

Hasin, Y., Seldin, M., and Lusis, A. (2017). Multi-omics approaches to disease. Genome Biol 18, 83. https://doi.org/10.1186/ s13059-017-1215-1

Hayes, B.M., Dulebohn, D.P., Sarkar, A., Tilly, K., Bestor, A., Ambroggio, X., and Rosa, P.A. (2014). Regulatory protein BBD18 of the lyme disease spirochete: essential role during tick acquisition? mBio 5, e01017-01014. https://doi.org/10.1128/mBio.01017-14

He, M., Ouyang, Z., Troxell, B., Xu, H., Moh, A., Piesman, J., Norgard, M.V., Gomelsky, M., and Yang, X.F. (2011). Cyclic di-GMP is essential for the survival of the lyme disease spirochete in ticks. PLoS Pathog 7 , e1002133. https://doi.org/10.1371/journal.ppat.1002133

He, M., Zhang, J.J., Ye, M., Lou, Y., and Yang, X.F. (2014). Cyclic Di-GMP receptor PlzA controls virulence gene expression through RpoS in Borrelia burgdorferi. Infect Immun 82, 445-452. https://doi.org/10.1128/ IAl.01238-13

He, Z.B., Cao, Y.Q., Yin, Y.P., Wang, Z.K., Chen, B., Peng, G.X., and Xia, Y.X. (2006). Role of hunchback in segment patterning of Locusta migratoria manilensis revealed by parental RNAi. Dev Growth Differ 48, 439-445. doi: 10.1111/j.1440-169X.2006.00881.x.

Heath, A.C. (1979). The temperature and humidity preferences of Haemaphysalis longicornis, Ixodes Holocyclus and Rhipicephalus sanguineus (Ixodidae): studies on eggs. Int J Parasitol 9, 33-39. doi: 10.1016/0020-7519(79)90063-8.

Hefty, P.S., Jolliff, S.E., Caimano, M.J., Wikel, S.K., Radolf, J.D., and Akins, D.R. (2001). Regulation of OspE-related, OspF-related, and Elp lipoproteins of Borrelia burgdorferi strain 297 by mammalian hostspecific signals. Infect Immun 69, 3618-3627. doi: 10.1128/IAI. 69.6.3618-3627.2001.

Hernandez-Jarguin, A., Diaz-Sanchez, S., Villar, M., and de la Fuente, J. (2018). Integrated metatranscriptomics and metaproteomics for the characterization of bacterial microbiota in unfed Ixodes ricinus. Ticks Tick Borne Dis 9, 1241-1251. https://doi.org/10.1016/j.ttbdis. 2018.04.020

Hill, C.A., and Wikel, S.K. (2005). The Ixodes scapularis Genome Project: an opportunity for advancing tick research. Trends Parasitol 21, 151-153. https://doi.org/10.1016/j.pt.2005.02.004

Hoffmann, J.A. (2003). The immune response of Drosophila. Nature 426, 33-38. https://doi.org/10.1038/nature02021

Hoffmann, J.A., Kafatos, F.C., Janeway, C.A., and Ezekowitz, R.A. (1999). Phylogenetic perspectives in innate immunity. Science 284, 1313-1318. doi: 10.1126/science.284.5418.1313.

Hoffmann, J.A., and Reichhart, J.M. (2002). Drosophila innate immunity: an evolutionary perspective. Nat Immunol 3, 121-126. https://doi.org/ 10.1038/ni0202-121
Hooper, L.V., Littman, D.R., and Macpherson, A.J. (2012). Interactions between the microbiota and the immune system. Science 336, 1268-1273. https://doi.org/10.1126/science.1223490

Hoxmeier, J.C., Fleshman, A.C., Broeckling, C.D., Prenni, J.E., Dolan, M.C., Gage, K.L., and Eisen, L. (2017). Metabolomics of the tickBorrelia interaction during the nymphal tick blood meal. Scientific reports 7, 44394. https://doi.org/10.1038/srep44394

Hubner, A., Revel, A.T., Nolen, D.M., Hagman, K.E., and Norgard, M.V. (2003). Expression of a luxS gene is not required for Borrelia burgdorferi infection of mice via needle inoculation. Infect Immun 71 , 2892-2896.

Hubner, A., Yang, X., Nolen, D.M., Popova, T.G., Cabello, F.C., and Norgard, M.V. (2001). Expression of Borrelia burgdorferi OspC and DbpA is controlled by a RpoN-RpoS regulatory pathway. Proc Natl Acad Sci U S A 98, 12724-12729.

Hynes, W.L., Ceraul, S.M., Todd, S.M., Seguin, K.C., and Sonenshine, D.E. (2005). A defensin-like gene expressed in the black-legged tick, Ixodes scapularis. Med Vet Entomol 19, 339-344. doi: 10.1111/j. 1365-2915.2005.00579.x.

lovinella, I., Ban, L., Song, L., Pelosi, P., and Dani, F.R. (2016). Proteomic analysis of castor bean tick Ixodes ricinus: a focus on chemosensory organs. Insect Biochem Mol Biol 78, 58-68. https://doi.org/10.1016/ j.ibmb. 2016.09.004

Irving, P., Troxler, L., Heuer, T.S., Belvin, M., Kopczynski, C., Reichhart, J.M., Hoffmann, J.A., and Hetru, C. (2001). A genome-wide analysis of immune responses in Drosophila. Proc Natl Acad Sci U S A 98, 15119-15124. https://doi.org/10.1073/pnas.261573998

Iyer, R., Caimano, M.J., Luthra, A., Axline, D., Jr., Corona, A., lacobas, D.A., Radolf, J.D., and Schwartz, I. (2015). Stage-specific global alterations in the transcriptomes of Lyme disease spirochetes during tick feeding and following mammalian host adaptation. Mol Microbiol 95, 509-538. https://doi.org/10.1111/mmi.12882

Jewett, M.W., Lawrence, K., Bestor, A.C., Tilly, K., Grimm, D., Shaw, P. VanRaden, M., Gherardini, F., and Rosa, P.A. (2007). The critical role of the linear plasmid Ip36 in the infectious cycle of Borrelia burgdorferi. Mol Microbiol 64, 1358-1374. doi: 10.1111/j.1365-2958.2007.05746.x.

Johns, R., Ohnishi, J., Broadwater, A., Sonenshine, D.E., De Silva, A.M., and Hynes, W.L. (2001). Contrasts in tick innate immune responses to Borrelia burgdorferi challenge: immunotolerance in Ixodes scapularis versus immunocompetence in Dermacentor variabilis (Acari: Ixodidae). J Med Entomol 38, 99-107. doi: 10.1603/0022-2585-38.1.99.

Jutras, B.L., Jones, G.S., Verma, A., Brown, N.A., Antonicello, A.D., Chenail, A.M., and Stevenson, B. (2013). Posttranscriptional selfregulation by the Lyme disease bacterium's BpuR DNA/RNA-binding protein. J Bacteriol 195, 4915-4923. https://doi.org/10.1128/JB. 00819-13

Jutras, B.L., Savage, C.R., Arnold, W.K., Lethbridge, K.G., Carroll, D.W., Tilly, K., Bestor, A., Zhu, H., Seshu, J., Zuckert, W.R., et al. (2019). The Lyme disease spirochete's BpuR DNA/RNA-binding protein is differentially expressed during the mammal-tick infectious cycle, which affects translation of the SodA superoxide dismutase. Mol Microbiol 112, 973-991. https://doi.org/10.1111/mmi.14336

Kamada, N., Seo, S.U., Chen, G.Y., and Nunez, G. (2013). Role of the gut microbiota in immunity and inflammatory disease. Nature reviews Immunology 13, 321-335. https://doi.org/10.1038/nri3430

Kariu, T., Smith, A., Yang, X., and Pal, U. (2013). A Chitin DeacetylaseLike Protein Is a Predominant Constituent of Tick Peritrophic Membrane That Influences the Persistence of Lyme Disease Pathogens within the Vector. PLoS ONE 8, e78376. https://doi.org/10.1371/journal.pone. 0078376

Kempfer, R., and Pombo, A. (2020). Methods for mapping 3D chromosome architecture. Nat Rev Genet 21, 207-226. https://doi.org/ 10.1038/s41576-019-0195-2

Khila, A., and Grbic, M. (2007). Gene silencing in the spider mite Tetranychus urticae: dsRNA and siRNA parental silencing of the Distal- 
less gene. Dev Genes Evol 217, 241-251. doi: 10.1007/ s00427-007-0132-9.

Kitsou, C., and Pal, U. (2018). Ixodes Immune Responses Against Lyme Disease Pathogens. Frontiers in cellular and infection microbiology 8 , 176. https://doi.org/10.3389/fcimb.2018.00176

Koci, J., Bernard, Q., Yang, X., and Pal, U. (2018). Borrelia burgdorferi surface protein Lmp1 facilitates pathogen dissemination through ticks as studied by an artificial membrane feeding system. Scientific reports 8, 1910. https://doi.org/10.1038/s41598-018-20208-4

Kopacek, P., Hajdusek, O., Buresova, V., and Daffre, S. (2010). Tick innate immunity. Adv Exp Med Biol 708, 137-162.

Kostick, J.L., Szkotnicki, L.T., Rogers, E.A., Bocci, P., Raffaelli, N., and Marconi, R.T. (2011). The diguanylate cyclase, Rrp1, regulates critical steps in the enzootic cycle of the Lyme disease spirochetes. Mol Microbiol 81, 219-231. https://doi.org/10.1111/j.1365-2958.2011.07687.x

Kostick-Dunn, J.L., Izac, J.R., Freedman, J.C., Szkotnicki, L.T., Oliver, L.D., Jr., and Marconi, R.T. (2018). The Borrelia burgdorferi c-di-GMP Binding Receptors, PlzA and PlzB, Are Functionally Distinct. Frontiers in cellular and infection microbiology 8, 213. https://doi.org/10.3389/fcimb. 2018.00213

Kotsyfakis, M., Kopacek, P., Franta, Z., Pedra, J.H., and Ribeiro, J.M. (2015). Deep Sequencing Analysis of the Ixodes ricinus Haemocytome. PLoS Negl Trop Dis 9, e0003754. https://doi.org/10.1371/journal.pntd. 0003754

Krause, P.J., Fish, D., Narasimhan, S., and Barbour, A.G. (2015). Borrelia miyamotoi infection in nature and in humans. Clinical microbiology and infection : the official publication of the European Society of Clinical Microbiology and Infectious Diseases 21, 631-639. https://doi.org/ 10.1016/j.cmi.2015.02.006

Kumar, D., Embers, M., Mather, T.N., and Karim, S. (2019). Is selenoprotein $\mathrm{K}$ required for Borrelia burgdorferi infection within the tick vector Ixodes scapularis? Parasites \& vectors 12, 289. https://doi.org/ 10.1186/s13071-019-3548-y

Kumar, M., Kaur, S., Kariu, T., Yang, X., Bossis, I., Anderson, J.F., and Pal, U. (2011). Borrelia burgdorferi BBA52 is a potential target for transmission blocking Lyme disease vaccine. Vaccine 29(48):9012-9, doi:10.1016/j.vaccine.2011.1009.1035.

Kumar, S., Molina-Cruz, A., Gupta, L., Rodrigues, J., and Barillas-Mury, C. (2010). A peroxidase/dual oxidase system modulates midgut epithelial immunity in Anopheles gambiae. Science 327, 1644-1648. https:// doi.org/10.1126/science. 1184008

Kung, F., Anguita, J., and Pal, U. (2013). Borrelia burgdorferi and tick proteins supporting pathogen persistence in the vector. Future Microbiol 8, 41-56. https://doi.org/10.2217/fmb.12.121

Kurokawa, C., Lynn, G.E., Pedra, J.H.F., Pal, U., Narasimhan, S., and Fikrig, E. (2020). Interactions between Borrelia burgdorferi and ticks. Nat Rev Microbiol. https://doi.org/10.1038/s41579-020-0400-5

La Manno, G. (2019). From single-cell RNA-seq to transcriptional regulation. Nat Biotechnol 37, 1421-1422. https://doi.org/10.1038/ s41587-019-0327-4

Lagal, V., Portnoi, D., Faure, G., Postic, D., and Baranton, G. (2006). Borrelia burgdorferi sensu stricto invasiveness is correlated with OspCplasminogen affinity. Microbes Infect 8, 645-652. doi: 10.1016/j.micinf. 2005.08.017.

Lam, T.T., Nguyen, T.P., Fikrig, E., and Flavell, R.A. (1994). A chromosomal Borrelia burgdorferi gene encodes a 22-kilodalton lipoprotein, P22, that is serologically recognized in Lyme disease. J Clin Microbiol 32, 876-883. doi: 10.1128/JCM.32.4.876-883.1994.

Landesman, W.J., Mulder, K., Fredericks, L.P., and Allan, B.F. (2019). Cross-kingdom analysis of nymphal-stage Ixodes scapularis microbial communities in relation to Borrelia burgdorferi infection and load. FEMS Microbiol Ecol 95. https://doi.org/10.1093/femsec/fiz167

Langhansova, H., Bopp, T., Schmitt, E., and Kopecky, J. (2015). Tick saliva increases production of three chemokines including monocyte chemoattractant protein-1, a histamine-releasing cytokine. Parasite Immunol 37, 92-96. https://doi.org/10.1111/pim.12168

Lemaitre, B., and Hoffmann, J. (2007). The host defense of Drosophila melanogaster. Annual review of immunology 25, 697-743. https:// doi.org/10.1146/annurev.immunol.25.022106.141615

Lewis, L.A., Radulovic, Z.M., Kim, T.K., Porter, L.M., and Mulenga, A. (2015). Identification of $24 \mathrm{~h}$ Ixodes scapularis immunogenic tick saliva proteins. Ticks Tick Borne Dis 6, 424-434. https://doi.org/10.1016/ j.ttbdis.2015.03.012

Ley, R.E., Lozupone, C.A., Hamady, M., Knight, R., and Gordon, J.I. (2008). Worlds within worlds: evolution of the vertebrate gut microbiota. Nat Rev Microbiol 6, 776-788. https://doi.org/10.1038/nrmicro1978

Li, X., Neelakanta, G., Liu, X., Beck, D.S., Kantor, F.S., Fish, D., Anderson, J.F., and Fikrig, E. (2007a). Role of outer surface protein $D$ in the Borrelia burgdorferi life cycle. Infect Immun 75, 4237-4244. doi: 10.1128/IAl.00632-07.

Li, X., Pal, U., Ramamoorthi, N., Liu, X., Desrosiers, D.C., Eggers, C.H., Anderson, J.F., Radolf, J.D., and Fikrig, E. (2007b). The Lyme disease agent Borrelia burgdorferi requires BB0690, a Dps homologue, to persist within ticks. Mol Microbiol 63(3), 694-710. doi: 10.1111/j. 1365-2958.2006.05550.x.

Liang, F.T., Brown, E.L., Wang, T., lozzo, R.V., and Fikrig, E. (2004). Protective niche for Borrelia burgdorferi to evade humoral immunity. The American journal of pathology 165, 977-985. doi: 10.1016/ S0002-9440(10)63359-7.

Liang, F.T., Jacobs, M.B., Bowers, L.C., and Philipp, M.T. (2002). An immune evasion mechanism for spirochetal persistence in Lyme borreliosis. J Exp Med 195, 415-422. doi: 10.1084/jem.20011870.

Lieberman-Aiden, E., van Berkum, N.L., Williams, L., Imakaev, M., Ragoczy, T., Telling, A., Amit, I., Lajoie, B.R., Sabo, P.J., Dorschner, M.O., et al. (2009). Comprehensive mapping of long-range interactions reveals folding principles of the human genome. Science 326, 289-293. https://doi.org/10.1126/science.1181369

Lin, Y.P., Tan, X., Caine, J.A., Castellanos, M., Chaconas, G., Coburn, J., and Leong, J.M. (2020). Strain-specific joint invasion and colonization by Lyme disease spirochetes is promoted by outer surface protein $\mathrm{C}$ PLoS Pathog 16, e1008516. https://doi.org/10.1371/journal.ppat. 1008516

Lisacek, F., Cohen-Boulakia, S., and Appel, R.D. (2006). Proteome informatics II: bioinformatics for comparative proteomics. Proteomics 6 , 5445-5466. https://doi.org/10.1002/pmic.200600275

Loginov, D.S., Loginova, Y.F., Dycka, F., Bottinger, K., Vechtova, P., and Sterba, J. (2019). Tissue-specific signatures in tick cell line MS profiles. Parasites \& vectors 12, 212. https://doi.org/10.1186/s13071-019-3460-5

Luo, R., and Zhao, H. (2012). Protein quantitation using iTRAQ: Review on the sources of variations and analysis of nonrandom missingness. Stat Interface 5, 99-107. https://doi.org/10.4310/sii.2012.v5.n1.a9

Lybecker, M.C., and Samuels, D.S. (2007). Temperature-induced regulation of RpoS by a small RNA in Borrelia burgdorferi. Mol Microbiol 64, 1075-1089. doi: 10.1111/j.1365-2958.2007.05716.x.

Mallory, K.L., Miller, D.P., Oliver, L.D., Jr., Freedman, J.C., Kostick-Dunn, J.L., Carlyon, J.A., Marion, J.D., Bell, J.K., and Marconi, R.T. (2016) Cyclic-di-GMP binding induces structural rearrangements in the PlzA and $\mathrm{PlzC}$ proteins of the Lyme disease and relapsing fever spirochetes: a possible switch mechanism for c-di-GMP-mediated effector functions. Pathogens and disease 74. https://doi.org/10.1093/femspd/ftw105

Mansfield, K.L., Cook, C., Ellis, R.J., Bell-Sakyi, L., Johnson, N., Alberdi, P., de la Fuente, J., and Fooks, A.R. (2017). Tick-borne pathogens induce differential expression of genes promoting cell survival and host resistance in Ixodes ricinus cells. Parasites \& vectors 10, 81. https:/l doi.org/10.1186/s13071-017-2011-1

Marchal, C., Schramm, F., Kern, A., Luft, B.J., Yang, X., Schuiit, T.J., Hovius, J.W., Jaulhac, B., and Boulanger, N. (2011). Antialarmin effect of tick saliva during the transmission of Lyme disease. Infect Immun 79, 774-785. https://doi.org//Al.00482-10 [pii] 10.1128/IAI.00482-10 
Marques, A. (2008). Chronic Lyme disease: a review. Infect Dis Clin North Am 22, 341-360, vii-viii. https://doi.org/10.1016/j.idc.2007.12.011

Marques, A.R. (2015). Laboratory diagnosis of Lyme disease: advances and challenges. Infect Dis Clin North Am 29, 295-307. https://doi.org/ 10.1016/j.idc.2015.02.005

Mbow, M.L., Gilmore, R.D., Jr., and Titus, R.G. (1999). An OspC-specific monoclonal antibody passively protects mice from tick-transmitted infection by Borrelia burgdorferi B31. Infect Immun 67, 5470-5472. doi: 10.1128/AAl.67.10.5470-5472.1999.

McClure Carroll, E.E., Wang, X., Shaw, D.K., O'Neal, A.J., Oliva Chavez, A.S., Brown, L.J., Boradia, V.M., Hammond, H.L., and Pedra, J.H.F. (2019). p47 licenses activation of the immune deficiency pathway in the tick Ixodes scapularis. Proc Natl Acad Sci U S A 116, 205-210. https:// doi.org/10.1073/pnas.1808905116

McNally, K.L., Mitzel, D.N., Anderson, J.M., Ribeiro, J.M., Valenzuela, J.G., Myers, T.G., Godinez, A., Wolfinbarger, J.B., Best, S.M., and Bloom, M.E. (2012). Differential salivary gland transcript expression profile in Ixodes scapularis nymphs upon feeding or flavivirus infection. Ticks Tick Borne Dis 3, 18-26. https://doi.org/10.1016/j.ttbdis. 2011.09.003

Mead, P.S. (2015). Epidemiology of Lyme disease. Infect Dis Clin North Am 29, 187-210. https://doi.org/10.1016/j.idc.2015.02.010

Miller, J.R., Koren, S., Dilley, K.A., Harkins, D.M., Stockwell, T.B., Shabman, R.S., and Sutton, G.G. (2018). A draft genome sequence for the Ixodes scapularis cell line, ISE6. F1000Res 7, 297. https://doi.org/ 10.12688/f1000research.13635.1

Molina-Cruz, A., DeJong, R.J., Charles, B., Gupta, L., Kumar, S., Jaramillo-Gutierrez, G., and Barillas-Mury, C. (2008). Reactive oxygen species modulate Anopheles gambiae immunity against bacteria and Plasmodium. J Biol Chem 283, 3217-3223. https://doi.org/10.1074/ jbc.M705873200

Mori, A., Konnai, S., Yamada, S., Hidano, A., Murase, Y., Ito, T., Takano, A., Kawabata, H., Onuma, M., and Ohashi, K. (2010). Two novel Salp15-like immunosuppressant genes from salivary glands of Ixodes persulcatus Schulze tick. Insect Mol Biol 19, 359-365. https://doi.org/ 10.1111/j.1365-2583.2010.00994.x

Morris, R.V., Shoemaker, C.B., David, J.R., Lanzaro, G.C., and Titus, R.G. (2001). Sandfly maxadilan exacerbates infection with Leishmania major and vaccinating against it protects against $L$. major infection. $\mathrm{J}$ Immunol 167, 5226-5230. doi: 10.4049/jimmunol.167.9.5226.

Munderloh, U.G., and Kurtti, T.J. (1995). Cellular and molecular interrelationships between ticks and prokaryotic tick-borne pathogens. Annu Rev Entomol 40, 221-243. doi: 10.1146/annurev.en. 40.010195.001253.

Munderloh, U.G., and Kurtti, T.J. (2005). The ABCs of Lyme disease spirochaetes in ticks. Lancet 366, 962-964. doi: 10.1016/ S0140-6736(05)67350-3.

Munderloh, U.G., Liu, Y., Wang, M., Chen, C., and Kurtti, T.J. (1994). Establishment, maintenance and description of cell lines from the tick Ixodes scapularis. J Parasitol 80, 533-543.

Murfin, K.E., Kleinbard, R., Aydin, M., Salazar, S.A., and Fikrig, E. (2019). Borrelia burgdorferi chemotaxis toward tick protein Salp12 contributes to acquisition. Ticks Tick Borne Dis 10, 1124-1134. https://doi.org/ 10.1016/j.ttbdis.2019.06.002

Myllymaki, H., Valanne, S., and Ramet, M. (2014). The Drosophila imd signaling pathway. J Immunol 192, 3455-3462. https://doi.org/10.4049/ jimmunol.1303309

Nadelman, R.B., and Wormser, G.P. (1998). Lyme borreliosis. Lancet 352, 557-565.

Nakajima, Y., Ogihara, K., Taylor, D., and Yamakawa, M. (2003). Antibacterial hemoglobin fragments from the midgut of the soft tick, Ornithodoros moubata (Acari: Argasidae). J Med Entomol 40, 78-81. doi: $10.1603 / 0022-2585-40.1 .78$.

Narasimhan, S., Coumou, J., Schuijt, T.J., Boder, E., Hovius, J.W., and Fikrig, E. (2014a). A tick gut protein with fibronectin III domains aids
Borrelia burgdorferi congregation to the gut during transmission. PLoS Pathog 10, e1004278. https://doi.org/10.1371/journal.ppat.1004278

Narasimhan, S., Deponte, K., Marcantonio, N., Liang, X., Royce, T.E., Nelson, K.F., Booth, C.J., Koski, B., Anderson, J.F., Kantor, F., et al. (2007). Immunity against Ixodes scapularis salivary proteins expressed within 24 hours of attachment thwarts tick feeding and impairs Borrelia transmission. doi: 10.1371/journal.pone.0000451. PLoS ONE 2, e451.

Narasimhan, S., and Fikrig, E. (2015). Tick microbiome: the force within. Trends Parasitol 31, 315-323. https://doi.org/10.1016/.pt.2015.03.010

Narasimhan, S., Rajeevan, N., Liu, L., Zhao, Y.O., Heisig, J., Pan, J., Eppler-Epstein, R., Deponte, K., Fish, D., and Fikrig, E. (2014b). Gut Microbiota of the Tick Vector Ixodes scapularis Modulate Colonization of the Lyme Disease Spirochete. Cell Host Microbe 15, 58-71. https:// doi.org/10.1016/j.chom.2013.12.001

Narasimhan, S., Santiago, F., Koski, R.A., Brei, B., Anderson, J.F., Fish, D., and Fikrig, E. (2002). Examination of the Borrelia burgdorferi transcriptome in Ixodes scapularis during feeding. J Bacteriol 184, 3122-3125

Narasimhan, S., Schuijt, T.J., Abraham, N.M., Rajeevan, N., Coumou, J., Graham, M., Robson, A., Wu, M.J., Daffre, S., Hovius, J.W., et al. (2017). Modulation of the tick gut milieu by a secreted tick protein favors Borrelia burgdorferi colonization. Nat Commun 8, 184. https:// doi.org/10.1038/s41467-017-00208-0

Neelakanta, G., Li, X., Pal, U., Liu, X., Beck, D.S., Deponte, K., Fish, D., Kantor, F.S., and Fikrig, E. (2007). Outer Surface Protein B Is Critical for Borrelia burgdorferi Adherence and Survival within Ixodes Ticks. PLoS Pathog 3, e33. doi: 10.1371/journal.ppat.0030033.

Nelder, M.P., Russell, C.B., Sheehan, N.J., Sander, B., Moore, S., Li, Y., Johnson, S., Patel, S.N., and Sider, D. (2016). Human pathogens associated with the blacklegged tick Ixodes scapularis: a systematic review. Parasites \& vectors 9, 265. https://doi.org/10.1186/ s13071-016-1529-y

Nogueira, S.V., Smith, A.A., Qin, J.H., and Pal, U. (2012). A surface enolase participates in Borrelia burgdorferi-plasminogen interaction and contributes to pathogen survival within feeding ticks. Infect Immun 80, 82-90. https://doi.org//Al.05671-11 [pii] 10.1128/IAl.05671-11

Novak, E.A., Sultan, S.Z., and Motaleb, M.A. (2014). The cyclic-di-GMP signaling pathway in the Lyme disease spirochete, Borrelia burgdorferi. Frontiers in cellular and infection microbiology 4, 56. https://doi.org/ 10.3389/fcimb.2014.00056

Nuttall, P.A. (2019). Tick saliva and its role in pathogen transmission. Wien Klin Wochenschr. https://doi.org/10.1007/s00508-019-1500-y

Ogden, N.H., Lindsay, L.R., Beauchamp, G., Charron, D., Maarouf, A., O'Callaghan, C.J., Waltner-Toews, D., and Barker, I.K. (2004) Investigation of relationships between temperature and developmental rates of tick Ixodes scapularis (Acari: Ixodidae) in the laboratory and field. J Med Entomol 41, 622-633. doi: 10.1603/0022-2585-41.4.622.

Ohnishi, J., Piesman, J., and de Silva, A.M. (2001). Antigenic and genetic heterogeneity of Borrelia burgdorferi populations transmitted by ticks. Proc Natl Acad Sci U S A 98, 670-675. doi: 10.1073/pnas.98.2.670.

Ojaimi, C., Brooks, C., Akins, D., Casjens, S., Rosa, P., Elias, A., Barbour, A., Jasinskas, A., Benach, J., Katonah, L., et al. (2002). Borrelia burgdorferi gene expression profiling with membrane-based arrays. Methods Enzymol 358, 165-177. doi: 10.1016/s0076-6879(02)58088-5.

Ojaimi, C., Brooks, C., Casjens, S., Rosa, P., Elias, A., Barbour, A., Jasinskas, A., Benach, J., Katona, L., Radolf, J., et al. (2003). Profiling of temperature-induced changes in Borrelia burgdorferi gene expression by using whole genome arrays. Infect Immun 71 , 1689-1705. doi: 10.1128/iai.71.4.1689-1705.2003.

Oliva Chavez, A.S., Shaw, D.K., Munderloh, U.G., and Pedra, J.H. (2017). Tick humoral responses: Marching to the beat of a different drummer. Front Microbiol 8, 223. https://doi.org/10.3389/fmicb.2017.00223

Oliver, J.D., Lynn, G.E., Burkhardt, N.Y., Price, L.D., Nelson, C.M., Kurtti, T.J., and Munderloh, U.G. (2016). Infection of Immature Ixodes 
scapularis (Acari: Ixodidae) by Membrane Feeding. J Med Entomol 53, 409-415. https://doi.org/10.1093/jme/tjv241

Onder, O., Humphrey, P.T., McOmber, B., Korobova, F., Francella, N., Greenbaum, D.C., and Brisson, D. (2012). OspC is potent plasminogen receptor on surface of Borrelia burgdorferi. J Biol Chem 287, 16860-16868. https://doi.org/M111.290775 [pii] 10.1074/ jbc.M111.290775

Onder, O., Shao, W., Lam, H., and Brisson, D. (2014). Tracking the sources of blood meals of parasitic arthropods using shotgun proteomics and unidentified tandem mass spectral libraries. Nat Protoc 9, 842-850. https://doi.org/10.1038/nprot.2014.048

Paddock, C.D., Lane, R.S., Staples, J.E., and Labruna, M.B. (2016) CHANGING PARADIGMS FOR TICK-BORNE DISEASES IN THE AMERICAS. National Academies of Sciences, Engineering, and Medicine Washington (DC): National Academies Press (US) Forum on Microbial Threats; Board on Global Health.

Pagel Van Zee, J., Geraci, N.S., Guerrero, F.D., Wikel, S.K., Stuart, J.J., Nene, V.M., and Hill, C.A. (2007). Tick genomics: the Ixodes genome project and beyond. Int J Parasitol 37, 1297-1305. https://doi.org/ 10.1016/j.jpara.2007.05.011

Pal, U., Dai, J., Li, X., Neelakanta, G., Luo, P., Kumar, M., Wang, P., Yang, X., Anderson, J.F., and Fikrig, E. (2008a). A Differential Role for BB0365 in the Persistence of Borrelia burgdorferi in Mice and Ticks. J Infect Dis 197, 148-155. doi: 10.1086/523764.

Pal, U., de Silva, A.M., Montgomery, R.R., Fish, D., Anguita, J., Anderson, J.F., Lobet, Y., and Fikrig, E. (2000). Attachment of Borrelia burgdorferi within Ixodes scapularis mediated by outer surface protein A. J Clin Invest 106, 561-569.

Pal, U., and Fikrig, E. (2003). Adaptation of Borrelia burgdorferi in the vector and vertebrate host. Microbes Infect 5, 659-666. doi: 10.1016/ s1286-4579(03)00097-2.

Pal, U., Li, X., Wang, T., Montgomery, R.R., Ramamoorthi, N., Desilva, A.M., Bao, F., Yang, $X$.,

Pypaert, M., Pradhan, D., et al. (2004a). TROSPA, an Ixodes scapularis receptor for Borrelia burgdorferi. Cell 119, 457-468. https://doi.org/ 10.1016/j.cell.2004.10.027

Pal, U., Montgomery, R.R., Lusitani, D., Voet, P., Weynants, V., Malawista, S.E., Lobet, Y., and Fikrig, E. (2001). Inhibition of Borrelia burgdorferitick Interactions in vivo by outer surface protein $A$ antibody. J Immunol 166, 7398-7403. doi: 10.4049/jimmunol.166.12.7398.

Pal, U., Wang, P., Bao, F., Yang, X., Samanta, S., Schoen, R., Wormser, G.P., Schwartz, I., and Fikrig, E. (2008b). Borrelia burgdorferi basic membrane proteins $A$ and $B$ participate in the genesis of Lyme arthritis. J Exp Med 205, 133-141. doi: 10.1084/jem.20070962.

Pal, U., Yang, X., Chen, M., Bockenstedt, L.K., Anderson, J.F., Flavell, R.A., Norgard, M.V., and Fikrig, E. (2004b). OspC facilitates Borrelia burgdorferi invasion of Ixodes scapularis salivary glands. J Clin Invest 113, 220-230. doi: 10.1172/JCl19894.

Pappas, C.J., Iyer, R., Petzke, M.M., Caimano, M.J., Radolf, J.D., and Schwartz, I. (2011). Borrelia burgdorferi requires glycerol for maximum fitness during the tick phase of the enzootic cycle. PLoS Pathog 7 , e1002102. https://doi.org/10.1371/journal.ppat.1002102PPATHOGENSD-11-00446 [pii]

Perner, J., Provaznik, J., Schrenkova, J., Urbanova, V., Ribeiro, J.M., and Kopacek, P. (2016). RNA-seq analyses of the midgut from blood- and serum-fed Ixodes ricinus ticks. Scientific reports 6, 36695. https:// doi.org/10.1038/srep36695

Phelan, J.P., Kern, A., Ramsey, M.E., Lundt, M.E., Sharma, B., Lin, T., Gao, L., Norris, S.J., Hyde, J.A., Skare, J.T., et al. (2019). Genomewide screen identifies novel genes required for Borrelia burgdorferi survival in its Ixodes tick vector. PLoS Pathog 15, e1007644. https:// doi.org/10.1371/journal.ppat.1007644

Piesman, J. (1993). Dynamics of Borrelia burgdorferi transmission by nymphal Ixodes dammini ticks. J Infect Dis 167, 1082-1085. doi: 10.1093/infdis/167.5.1082.
Piesman, J., and Gern, L. (2004). Lyme borreliosis in Europe and North America. Parasitology 129 Suppl, S191-220. doi: 10.1017/ s0031182003004694.

Piesman, J., Oliver, J., and Sinsky, R. (1990). Growth kinetics of the Lyme disease spirochete (Borrelia burgdorferi) in vector ticks (Ixodes dammini). Am J Trop med Hyg 42, 352-357. doi: 10.4269/ajtmh. 1990.42.352.

Piesman, J., Schneider, B.S., and Zeidner, N.S. (2001). Use of quantitative PCR to measure density of Borrelia burgdorferi in the midgut and salivary glands of feeding tick vectors. J Clin Microbiol 39, 4145-4148. doi: 10.1128/JCM.39.11.4145-4148.2001.

Pimenta, P.F., Modi, G.B., Pereira, S.T., Shahabuddin, M., and Sacks, D.L. (1997). A novel role for the peritrophic matrix in protecting Leishmania from the hydrolytic activities of the sand fly midgut. Parasitology 115 (Pt 4), 359-369.

Pitzer, J.E., Sultan, S.Z., Hayakawa, Y., Hobbs, G., Miller, M.R., and Motaleb, M.A. (2011). Analysis of the Borrelia burgdorferi cyclic-diGMP-binding protein PlzA reveals a role in motility and virulence. Infect Immun 79, 1815-1825. https://doi.org//Al.00075-11

Pritt, B.S., Mead, P.S., Johnson, D.K., Neitzel, D.F., Respicio-Kingry, L.B., Davis, J.P., Schiffman, E., Sloan, L.M., Schriefer, M.E., Replogle, A.J., et al. (2016). Identification of a novel pathogenic Borrelia species causing Lyme borreliosis with unusually high spirochaetaemia: a descriptive study. Lancet Infect Dis. https://doi.org/10.1016/ S1473-3099(15)00464-8

Purser, J.E., Lawrenz, M.B., Caimano, M.J., Howell, J.K., Radolf, J.D., and Norris, S.J. (2003). A plasmid-encoded nicotinamidase (PncA) is essential for infectivity of Borrelia burgdorferi in a mammalian host. Mol Microbiol 48, 753-764. doi: 10.1046/j.1365-2958.2003.03452.x.

Purser, J.E., and Norris, S.J. (2000). Correlation between plasmid content and infectivity in Borrelia burgdorferi. Proc Natl Acad Sci U S A 97, 13865-13870. doi: 10.1073/pnas.97.25.13865.

Radolf, J.D., Caimano, M.J., Stevenson, B., and Hu, L.T. (2012). Of ticks, mice and men: understanding the dual-host lifestyle of Lyme disease spirochaetes. Nat Rev Microbiol 10, 87-99. https://doi.org/nrmicro2714 [pii] 10.1038/nrmicro2714

Radolf J.D. and Samuels, D.S. (2021). Lyme Disease and Relapsing Fever Spirochetes: Genomics, Molecular Biology, Host Interactions and Disease Pathogenesis (Norfolk, UK: Caister Academic Press). https:// doi.org/10.21775/9781913652616

Ramamoorthi, N., Narasimhan, S., Pal, U., Bao, F., Yang, X.F., Fish, D. Anguita, J., Norgard, M.V., Kantor, F.S., Anderson, J.F., et al. (2005). The Lyme disease agent exploits a tick protein to infect the mammalian host. Nature 436, 573-577. https://doi.org/10.1038/nature03812

Rego, R.O.M., Trentelman, J.J.A., Anguita, J., Nijhof, A.M., Sprong, H., Klempa, B., Hajdusek, O., Tomas-Cortazar, J., Azagi, T., Strnad, M., et al. (2019). Counterattacking the tick bite: towards a rational design of anti-tick vaccines targeting pathogen transmission. Parasites \& vectors 12, 229. https://doi.org/10.1186/s13071-019-3468-x

Revel, A.T., Blevins, J.S., Almazan, C., Neil, L., Kocan, K.M., de la Fuente, J., Hagman, K.E., and Norgard, M.V. (2005). bptA (bbe16) is essential for the persistence of the Lyme disease spirochete, Borrelia burgdorferi, in its natural tick vector. Proc Natl Acad Sci U S A 102, 6972-6977. doi: 10.1073/pnas.0502565102.

Revel, A.T., Talaat, A.M., and Norgard, M.V. (2002). DNA microarray analysis of differential gene expression in Borrelia burgdorferi, the Lyme disease spirochete. Proc Natl Acad Sci U S A 99, 1562-1567. doi: 10.1073/pnas.032667699.

Ribeiro, J.M., Alarcon-Chaidez, F., Francischetti, I.M., Mans, B.J., Mather, T.N., Valenzuela, J.G., and Wikel, S.K. (2006). An annotated catalog of salivary gland transcripts from Ixodes scapularis ticks. Insect Biochem Mol Biol 36, 111-129.

Ribeiro, J.M., and Francischetti, I.M. (2003). Role of arthropod saliva in blood feeding: sialome and post-sialome perspectives. Annu Rev Entomol 48, 73-88. doi: 10.1146/annurev.ento.48.060402.102812. 
Rivera, M. (2017). Bacterioferritin: Structure, Dynamics, and ProteinProtein Interactions at Play in Iron Storage and Mobilization. Acc Chem Res 50, 331-340. https://doi.org/10.1021/acs.accounts.6b00514.

Rogers, E.A., Terekhova, D., Zhang, H.M., Hovis, K.M., Schwartz, I., and Marconi, R.T. (2009). Rrp1, a cyclic-di-GMP-producing response regulator, is an important regulator of Borrelia burgdorferi core cellular functions. Mol Microbiol 71, 1551-1573. https://doi.org/MMl6621 [pii]10.1111/j.1365-2958.2009.06621.x

Rosa, P. (2005). Lyme disease agent borrows a practical coat. Nat Med 11, 831-832. doi: 10.1038/nm0805-831.

Rosa, P.A., Tilly, K., and Stewart, P.E. (2005). The burgeoning molecular genetics of the Lyme disease spirochaete. Nat Rev Microbiol 3, 129-143. doi: $10.1038 /$ nrmicro1086.

Round, J.L., and Mazmanian, S.K. (2009). The gut microbiota shapes intestinal immune responses during health and disease. Nature reviews Immunology 9, 313-323. https://doi.org/10.1038/nri2515

Rudenko, N., Golovchenko, M., Edwards, M.J., and Grubhoffer, L. (2005). Differential expression of Ixodes ricinus tick genes induced by blood feeding or Borrelia burgdorferi infection. J Med Entomol 42, 36-41. doi: 10.1093/jmedent/42.1.36.

Rudenko, N., Golovchenko, M., Vancova, M., Clark, K., Grubhoffer, L., and Oliver, J.H., Jr. (2016). Isolation of live Borrelia burgdorferi sensu lato spirochaetes from patients with undefined disorders and symptoms not typical for Lyme borreliosis. Clinical microbiology and infection 22, 267 e269-267 e215. https://doi.org/10.1016/..cmi.2015.11.009

Rudzinska, M.A., Spielman, A., Lewengrub, S., Piesman, J., and Karakashian, S. (1982). Penetration of the peritrophic membrane of the tick by Babesia microti. Cell Tissue Res 221, 471-481. doi: 10.1007/ BF00215696.

Samuels, D.S. (2011). Gene regulation in Borrelia burgdorferi. Annu Rev Microbiol 65, 479-499. https://doi.org/10.1146/annurev.micro. 112408.134040

Samuels, D.S., Drecktrah, D., and Hall, L.S. (2018). Genetic Transformation and Complementation. Methods Mol Biol 1690, 183-200. https://doi.org/10.1007/978-1-4939-7383-5_15

Sauer, J.R.a.H., A.J (1986). Morphology, Physiology and Biology of Ticks, Vol Vol-1 (New York: Ellis Horwood Limited and John Wiley and Sons).

Schuijt, T.J., Coumou, J., Narasimhan, S., Dai, J., Deponte, K., Wouters, D., Brouwer, M., Oei, A., Roelofs, J.J., van Dam, A.P., et al. (2011). A tick mannose-binding lectin inhibitor interferes with the vertebrate complement cascade to enhance transmission of the lyme disease agent. Cell Host Microbe 10, 136-146. https://doi.org/10.1016/j.chom. 2011.06.010

Schutzer, S.E., Fraser-Liggett, C.M., Casjens, S.R., Qiu, W.G., Dunn, J.J., Mongodin, E.F., and Luft, B.J. (2011). Whole-genome sequences of thirteen isolates of Borrelia burgdorferi. J Bacteriol 193, 1018-1020. https://doi.org/JB.01158-10

Schwan, T.G. (2003). Temporal regulation of outer surface proteins of the Lyme-disease spirochaete Borrelia burgdorferi. Biochemical Society transactions 31, 108-112. DOI: 10.1042/bst0310108

Schwan, T.G., and Piesman, J. (2000). Temporal changes in outer surface proteins $\mathrm{A}$ and $\mathrm{C}$ of the Lyme disease- associated spirochete, Borrelia burgdorferi, during the chain of infection in ticks and mice. J Clin Microbiol 38, 382-388

Schwan, T.G., and Piesman, J. (2002). Vector interactions and molecular adaptations of Lyme disease and relapsing fever spirochetes associated with transmission by ticks. Emerg Infect Dis 8, 115-121. DOI: 10.3201/eid0802.010198

Schwan, T.G., Piesman, J., Golde, W.T., Dolan, M.C., and Rosa, P.A. (1995). Induction of an outer surface protein on Borrelia burgdorferi during tick feeding. Proc Natl Acad Sci U S A 92, 2909-2913. doi: 10.1073/pnas.92.7.2909.

Schwarz, A., Tenzer, S., Hackenberg, M., Erhart, J., Gerhold-Ay, A., Mazur, J., Kuharev, J., Ribeiro, J.M., and Kotsyfakis, M. (2014). A systems level analysis reveals transcriptomic and proteomic complexity in Ixodes ricinus midgut and salivary glands during early attachment and feeding. Mol Cell Proteomics 13, 2725-2735. https://doi.org/ 10.1074/mcp.M114.039289

Schwarz, A., von Reumont, B.M., Erhart, J., Chagas, A.C., Ribeiro, J.M and Kotsyfakis, M. (2013). De novo Ixodes ricinus salivary gland transcriptome analysis using two next-generation sequencing methodologies. FASEB J 27, 4745-4756. https://doi.org/10.1096/fj. 13-232140

Seger, C., and Salzmann, L. (2020). After another decade: LC-MS/MS became routine in clinical diagnostics. Clinical biochemistry. https:/l doi.org/10.1016/j.clinbiochem.2020.03.004

Shaw, D.K., Tate, A.T., Schneider, D.S., Levashina, E.A., Kagan, J.C., Pal, U., Fikrig, E., and Pedra, J.H.F. (2018). Vector Immunity and Evolutionary Ecology: The Harmonious Dissonance. Trends Immunol 39, 862-873. https://doi.org/10.1016/j.it.2018.09.003

Shaw, D.K., Wang, X., Brown, L.J., Chavez, A.S., Reif, K.E., Smith, A.A., Scott, A.J., McClure, E.E., Boradia, V.M., Hammond, H.L., et al. (2017) Infection-derived lipids elicit an immune deficiency circuit in arthropods. Nat Commun 8, 14401. https://doi.org/10.1038/ncomms14401

Shi, Y., Xu, Q., McShan, K., and Liang, F.T. (2008). Both decorin-binding proteins $A$ and $B$ are critical for the overall virulence of Borrelia burgdorferi. Infect Immun 76, 1239-1246. doi: 10.1128/IAl.00897-07. Epub 2008 Jan 14.

Shi, Y., Xu, Q., Seemanapalli, S.V., McShan, K., and Liang, F.T. (2006). The dbpBA locus of Borrelia burgdorferi is not essential for infection of mice. Infect Immun 74, 6509-6512. doi: 10.1128/IAI.00740-06

Sigal, L.H., Zahradnik, J.M., Lavin, P., Patella, S.J., Bryant, G., Haselby, R., Hilton, E., Kunkel, M., Adler-Klein, D., Doherty, T., et al. (1998). A vaccine consisting of recombinant Borrelia burgdorferi outer-surface protein A to prevent Lyme disease. N Engl J Med 339, 216-222. doi: 10.1056/NEJM199807233390402.

Simo, L., Kazimirova, M., Richardson, J., and Bonnet, S.I. (2017). The Essential Role of Tick Salivary Glands and Saliva in Tick Feeding and Pathogen Transmission. Frontiers in cellular and infection microbiology 7, 281. https://doi.org/10.3389/fcimb.2017.00281

Skinnider, M.A., Squair, J.W., and Foster, L.J. (2019). Evaluating measures of association for single-cell transcriptomics. Nat Methods 16, 381-386. https://doi.org/10.1038/s41592-019-0372-4

Smith, A.A., Navasa, N., Yang, X., Wilder, C.N., Buyuktanir, O., Marques, A., Anguita, J., and Pal, U. (2016). Cross-Species Interferon Signaling Boosts Microbicidal Activity within the Tick Vector. Cell Host Microbe 20 , 91-98. https://doi.org/10.1016/j.chom.2016.06.001

Smith, A.A., and Pal, U. (2014). Immunity-related genes in Ixodes scapularis--perspectives from genome information. Frontiers in cellular and infection microbiology 4, 116. https://doi.org/10.3389/fcimb. 2014.00116

Soares, C.A., Lima, C.M., Dolan, M.C., Piesman, J., Beard, C.B., and Zeidner, N.S. (2005). Capillary feeding of specific dsRNA induces silencing of the isac gene in nymphal Ixodes scapularis ticks. Insect Mol Biol 14, 443-452. doi: 10.1111/j.1365-2583.2005.00575.x.

Sonenshine, D.E. (1993). Biology of Ticks, Vol Vol-1 (New York: Oxford University Press)

Sonenshine, D.E., Ceraul, S.M., Hynes, W.E., Macaluso, K.R., and Azad, A.F. (2002). Expression of defensin-like peptides in tick hemolymph and midgut in response to challenge with Borrelia burgdorferi, Escherichia coli and Bacillus subtilis. Exp Appl Acarol 28, 127-134. doi: 10.1023/a: 1025354326877

Srivastava, S.Y., and de Silva, A.M. (2008). Reciprocal expression of ospA and $\mathrm{ospC}$ in single cells of Borrelia burgdorferi. J Bacteriol 190, 3429-3433. doi: 10.1128/JB.00085-08

Stanek, G., and Strle, F. (2018). Lyme borreliosis-from tick bite to diagnosis and treatment. FEMS Microbiol Rev 42, 233-258. https:// doi.org/10.1093/femsre/fux047 
Stark, R., Grzelak, M., and Hadfield, J. (2019). RNA sequencing: the teenage years. Nat Rev Genet 20, 631-656. https://doi.org/10.1038/ s41576-019-0150-2

Steere, A.C. (2001). Lyme disease. N Engl J Med 345, 115-125. doi: 10.1056/NEJM200107123450207.

Steere, A.C., Coburn, J., and Glickstein, L. (2004). The emergence of Lyme disease. J Clin Invest 113, 1093-1101. doi: 10.1172/JCl21681.

Steere, A.C., Sikand, V.K., Meurice, F., Parenti, D.L., Fikrig, E., Schoen, R.T., Nowakowski, J., Schmid, C.H., Laukamp, S., Buscarino, C., et al. (1998). Vaccination against Lyme disease with recombinant Borrelia burgdorferi outer-surface lipoprotein A with adjuvant. N Engl J Med 339, 209-215. doi: 10.1056/NEJM199807233390401.

Steere, A.C., Strle, F., Wormser, G.P., Hu, L.T., Branda, J.A., Hovius, J.W., Li, X., and Mead, P.S. (2016). Lyme borreliosis. Nat Rev Dis Primers 2, 16090. https://doi.org/10.1038/nrdp.2016.90

Stevenson, B., and Seshu, J. (2018). Regulation of gene and protein expression in the Lyme disease spirochete. Curr Top Microbiol Immunol 415, 83-112. https://doi.org/10.1007/82_2017_49

Stewart, P.E., Bestor, A., Cullen, J.N., and Rosa, P.A. (2008). A tightly regulated surface protein of Borrelia burgdorferi is not essential to the mouse-tick infectious cycle. Infect Immun 76, 1970-1978. doi: 10.1128/ IAl.00714-07.

Stewart, P.E., and Bloom, M.E. (2020). Sharing the Ride: Ixodes scapularis Symbionts and Their Interactions. Frontiers in cellular and infection microbiology 10, 142. https://doi.org/10.3389/fcimb. 2020.00142

Stewart, P.E., Byram, R., Grimm, D., Tilly, K., and Rosa, P.A. (2005). The plasmids of Borrelia burgdorferi: essential genetic elements of a pathogen. Plasmid 53, 1-13. doi: 10.1016/j.plasmid.2004.10.006.

Stewart, P.E., Wang, X., Bueschel, D.M., Clifton, D.R., Grimm, D., Tilly, K., Carroll, J.A., Weis, J.J., and Rosa, P.A. (2006). Delineating the requirement for the Borrelia burgdorferi virulence factor $\mathrm{OspC}$ in the mammalian host. Infect Immun 74, 3547-3553. doi: 10.1128/IAI. 00158-06.

Strother, K.O., Broadwater, A., and De Silva, A. (2005). Plasmid requirements for infection of ticks by Borrelia burgdorferi. Vector Borne Zoonotic Dis 5, 237-245. doi: 10.1089/vbz.2005.5.237.

Strother, K.O., and de Silva, A. (2005). Role of Borrelia burgdorferi linear plasmid 25 in infection of Ixodes scapularis ticks. J Bacteriol 187, 5776-5781. doi: 10.1128/JB.187.16.5776-5781.2005.

Sultana, H., Patel, U., Toliver, M., Maggi, R.G., and Neelakanta, G. (2016). Molecular identification and bioinformatics analysis of a potential antivector vaccine candidate, $15-k D a$ salivary gland protein (Salp15), from Ixodes affinis ticks. Ticks Tick Borne Dis 7, 46-53. https://doi.org/ 10.1016/..ttbdis.2015.08.003

Sun, D., Guo, Z., Liu, Y., and Zhang, Y. (2017). Progress and Prospects of CRISPR/Cas Systems in Insects and Other Arthropods. Front Physiol 8, 608. https://doi.org/10.3389/fphys.2017.00608

Swei, A., and Kwan, J.Y. (2017). Tick microbiome and pathogen acquisition altered by host blood meal. The ISME journal 11, 813-816. https://doi.org/10.1038/ismej.2016.152

Sze, C.W., Smith, A., Choi, Y.H., Yang, X., Pal, U., Yu, A., and Li, C. (2013). Study of the response regulator Rrp1 reveals its regulatory role in chitobiose utilization and virulence of Borrelia burgdorferi. Infect Immun 81, 1775-1787. https://doi.org/10.1128/IAI.00050-13

Tilly, K., Bestor, A., Jewett, M.W., and Rosa, P. (2007). Rapid clearance of Lyme disease spirochetes lacking OspC from skin. Infect Immun 75, 1517-1519. doi: 10.1128/IAl.01725-06

Tilly, K., Grimm, D., Bueschel, D.M., Krum, J.G., and Rosa, P. (2004). Infectious cycle analysis of a Borrelia burgdorferi mutant defective in transport of chitobiose, a tick cuticle component. Vector Borne Zoonotic Dis 4, 159-168. doi: 10.1089/1530366041210738

Tilly, K., Krum, J.G., Bestor, A., Jewett, M.W., Grimm, D., Bueschel, D., Byram, R., Dorward, D., Vanraden, M.J., Stewart, P., et al. (2006). Borrelia burgdorferi OspC protein required exclusively in a crucial early stage of mammalian infection. Infect Immun 74, 3554-3564. doi: 10.1128/IAl.01950-05.

Tokarz, R., Anderton, J.M., Katona, L.I., and Benach, J.L. (2004). Combined effects of blood and temperature shift on Borrelia burgdorferi gene expression as determined by whole genome DNA array. Infect Immun 72, 5419-5432. doi: 10.1128/IAl.72.9.5419-5432

Tokarz, R., Tagliafierro, T., Sameroff, S., Cucura, D.M., Oleynik, A., Che, X., Jain, K., and Lipkin, W.I. (2019). Microbiome analysis of Ixodes scapularis ticks from New York and Connecticut. Ticks Tick Borne Dis 10, 894-900. https://doi.org/10.1016/j.ttbdis.2019.04.011

Toledo, A., Coleman, J.L., Kuhlow, C.J., Crowley, J.T., and Benach, J.L. (2011). The enolase of Borrelia burgdorferi is a plasminogen receptor released in outer membrane vesicles. Infect Immun 80, 359-368. https://doi.org//Al.05836-11 [pii] 10.1128//Al.05836-11

Tonk, M., Cabezas-Cruz, A., Valdes, J.J., Rego, R.O., Chrudimska, T., Strnad, M., Sima, R., Bell-Sakyi, L., Franta, Z., Vilcinskas, A., et al. (2014a). Defensins from the tick /xodes scapularis are effective against phytopathogenic fungi and the human bacterial pathogen Listeria grayi. Parasites \& vectors 7, 554. https://doi.org/10.1186/s13071-014-0554-y

Tonk, M., Cabezas-Cruz, A., Valdes, J.J., Rego, R.O., Rudenko, N., Golovchenko, M., Bell-Sakyi, L., de la Fuente, J., and Grubhoffer, L. (2014b). Identification and partial characterisation of new members of the Ixodes ricinus defensin family. Gene 540, 146-152. https://doi.org/ 10.1016/j.gene.2014.03.002

Tyson, K., Elkins, C., Patterson, H., Fikrig, E., and de Silva, A. (2007). Biochemical and functional characterization of Salp20, an Ixodes scapularis tick salivary protein that inhibits the complement pathway. Insect Mol Biol 16, 469-479. doi: 10.1111/j.1365-2583.2007.00742.x.

Ueti, M.W., Reagan, J.O., Jr., Knowles, D.P., Jr., Scoles, G.A., Shkap, V., and Palmer, G.H. (2007). Identification of midgut and salivary glands as specific and distinct barriers to efficient tick-borne transmission of Anaplasma marginale. Infect Immun 75, 2959-2964.

Ullmann, A.J., Lima, C.M., Guerrero, F.D., Piesman, J., and Black, W.C.t. (2005). Genome size and organization in the blacklegged tick, Ixodes scapularis and the Southern cattle tick, Boophilus microplus. Insect Mol Biol 14, 217-222. doi: 10.1111/j.1365-2583.2005.00551.x.

Valanne, S., Wang, J.H., and Ramet, M. (2011). The Drosophila Toll signaling pathway. J Immunol 186, 649-656. https://doi.org/10.4049/ jimmunol.1002302

Valdes, J.J., Cabezas-Cruz, A., Sima, R., Butterill, P.T., Ruzek, D., and Nuttall, P.A. (2016). Substrate prediction of Ixodes ricinus salivary lipocalins differentially expressed during Borrelia afzelii infection. Scientific reports 6, 32372. https://doi.org/10.1038/srep32372

Valenzuela, J.G., Belkaid, Y., Garfield, M.K., Mendez, S., Kamhawi, S., Rowton, E.D., Sacks, D.L., and Ribeiro, J.M. (2001). Toward a defined anti-Leishmania vaccine targeting vector antigens: characterization of a protective salivary protein. J Exp Med 194, 331-342. doi: 10.1084/jem. 194.3.331.

Vechtova, P., Sterbova, J., Sterba, J., Vancova, M., Rego, R.O.M., Selinger, M., Strnad, M., Golovchenko, M., Rudenko, N., and Grubhoffer, L. (2018). A bite so sweet: the glycobiology interface of tickhost-pathogen interactions. Parasites \& vectors 11,594 . https://doi.org/ 10.1186/s13071-018-3062-7

Venken, K.J., and Bellen, H.J. (2005). Emerging technologies for gene manipulation in Drosophila melanogaster. Nat Rev Genet 6, 167-178. doi: $10.1038 / \mathrm{nrg} 1553$.

von Lackum, K., Ollison, K.M., Bykowski, T., Nowalk, A.J., Hughes, J.L., Carroll, J.A., Zuckert, W.R., and Stevenson, B. (2007). Regulated synthesis of the Borrelia burgdorferi inner-membrane lipoprotein IpLA7 (P22, P22-A) during the Lyme disease spirochaete's mammal-tick infectious cycle. Microbiology 153, 1361-1371. https://doi.org/ $153 / 5 / 1361$

Vu Hai, V., Pages, F., Boulanger, N., Audebert, S., Parola, P., and Almeras, L. (2013). Immunoproteomic identification of antigenic salivary 
biomarkers detected by Ixodes ricinus-exposed rabbit sera. Ticks Tick Borne Dis 4, 459-468. https://doi.org/10.1016/j.ttbdis.2013.06.001

Wagemakers, A., Coumou, J., Schuijt, T.J., Oei, A., Nijhof, A.M., van 't Veer, C., van der Poll, T., Bins, A.D., and Hovius, J.W. (2016). An Ixodes ricinus Tick Salivary Lectin Pathway Inhibitor Protects Borrelia burgdorferi sensu lato from Human Complement. Vector Borne Zoonotic Dis 16, 223-228. https://doi.org/10.1089/vbz.2015.1901

Wang, P., Lutton, A., Olesik, J., Vali, H., and Li, X. (2012). A novel iron- and copper-binding protein in the Lyme disease spirochaete. Mol Microbiol 86, 1441-1451. https://doi.org/10.1111/mmi.12068

Wang, Q., Sun, Q., Czajkowsky, D.M., and Shao, Z. (2018). Sub-kb Hi-C in $D$. melanogaster reveals conserved characteristics of TADs between insect and mammalian cells. Nat Commun 9, 188. https://doi.org/ 10.1038/s41467-017-02526-9

Wang, Y., and Zhu, S. (2011). The defensin gene family expansion in the tick Ixodes scapularis. Dev Comp Immunol 35, 1128-1134. https:// doi.org/10.1016/j.dci.2011.03.030

Wang, Z., Gerstein, M., and Snyder, M. (2009). RNA-Seq: a revolutionary tool for transcriptomics. Nat Rev Genet 10, 57-63. https://doi.org/ 10.1038/nrg2484

Weisheit, S., Villar, M., Tykalova, H., Popara, M., Loecherbach, J., Watson, M., Ruzek, D., Grubhoffer, L., de la Fuente, J., Fazakerley, J.K., et al. (2015). Ixodes scapularis and Ixodes ricinus tick cell lines respond to infection with tick-borne encephalitis virus: transcriptomic and proteomic analysis. Parasites \& vectors 8, 599. https://doi.org/ 10.1186/s13071-015-1210-x

Wilke, A.B., and Marrelli, M.T. (2015). Paratransgenesis: a promising new strategy for mosquito vector control. Parasites \& vectors 8, 342. https:// doi.org/10.1186/s13071-015-0959-2

Wilske, B. (2005). Epidemiology and diagnosis of Lyme borreliosis. Ann Med 37, 568-579.

Wilske, B., Busch, U., Fingerle, V., Jauris-Heipke, S., Preac Mursic, V., Rossler, D., and Will, G. (1996). Immunological and molecular variability of OspA and OspC. Implications for Borrelia vaccine development. Infection 24, 208-212. doi: 10.1007/BF01713341.

Wilske, B., Fingerle, V., Herzer, P., Hofmann, A., Lehnert, G., Peters, H., Pfister, H.W., Preac-Mursic, V., Soutschek, E., and Weber, K. (1993). Recombinant immunoblot in the serodiagnosis of Lyme borreliosis. Comparison with indirect immunofluorescence and enzyme-linked immunosorbent assay. Med Microbiol Immunol 182, 255-270. DOI: 10.1007/BF00579624

Wormser, G.P., Dattwyler, R.J., Shapiro, E.D., Halperin, J.J., Steere, A.C., Klempner, M.S., Krause, P.J., Bakken, J.S., Strle, F., Stanek, G., et al. (2006). The clinical assessment, treatment, and prevention of lyme disease, human granulocytic anaplasmosis, and babesiosis: clinical practice guidelines by the Infectious Diseases Society of America. Clin Infect Dis 43, 1089-1134. https://doi.org/10.1086/508667
Xu, Q., McShan, K., and Liang, F.T. (2007). Identification of an ospC operator critical for immune evasion of Borrelia burgdorferi. Mol Microbiol 64, 220-231. doi: 10.1111/j.1365-2958.2007.05636.x.

Yang, X., Coleman, A.S., Anguita, J., and Pal, U. (2009). A chromosomally encoded virulence factor protects the Lyme disease pathogen against host-adaptive immunity. PLoS Pathog 5, e1000326. doi: 10.1371/ journal.ppat.1000326.

Yang, X., Lenhart, T.R., Kariu, T., Anguita, J., Akins, D.R., and Pal, U. (2010). Characterization of unique regions of Borrelia burgdorferi surface-located membrane protein 1. Infect Immun 78, 4477-4487. https://doi.org//Al.00501-10

Yang, X., Promnares, K., Qin, J., He, M., Shroder, D.Y., Kariu, T., Wang, Y., and Pal, U. (2011). Characterization of Multiprotein Complexes of the Borrelia burgdorferi Outer Membrane Vesicles. J Proteome Res 10, 4556-4566. https://doi.org/10.1021/pr200395b

Yang, X., Qin, J., Promnares, K., Kariu, T., Anderson, J.F., and Pal, U. (2013). Novel microbial virulence factor triggers murine lyme arthritis. J Infect Dis 207, 907-918. https://doi.org/10.1093/infdis/jis930

Yang, X., Smith, A.A., Williams, M.S., and Pal, U. (2014). A dityrosine network mediated by dual oxidase and peroxidase influences the persistence of Lyme disease pathogens within the vector. J Biol Chem 289, 12813-12822. https://doi.org/10.1074/jbc.M113.538272

Yang, X., Thakur, M., Koci, J., Smith, A.A., Singh, P., Zhuang, X., Promnares, K., Wang, Y., Buyuktanir, O., and Pal, U. (2018). Analysis of Borrelia burgdorferi proteome and protein-protein interactions. Methods Mol Biol 1690, 259-277. https://doi.org/10.1007/978-1-4939-7383-5_19

Yang, X.F., Alani, S.M., and Norgard, M.V. (2003). The response regulator Rrp2 is essential for the expression of major membrane lipoproteins in Borrelia burgdorferi. Proc Natl Acad Sci U S A 100, 11001-11006. doi: 10.1073/pnas.1834315100.

Yang, X.F., Pal, U., Alani, S.M., Fikrig, E., and Norgard, M.V. (2004). Essential role for OspA/B in the life cycle of the Lyme disease spirochete. J Exp Med 199, 641-648. doi: 10.1084/jem.20031960

Zhang, J.J., Chen, T., Yang, Y., Du, J., Li, H., Troxell, B., He, M., Carrasco, S.E., Gomelsky, M., and Yang, X.F. (2018). Positive and negative regulation of glycerol utilization by the c-di-GMP binding protein PlzA in Borrelia burgdorferi. J Bacteriol 200. https://doi.org/10.1128/JB. 00243-18

Zhang, L., Zhang, Y., Adusumilli, S., Liu, L., Narasimhan, S., Dai, J., Zhao, Y.O., and Fikrig, E. (2011). Molecular interactions that enable movement of the Lyme disease agent from the tick gut into the hemolymph. PLoS Pathog 7, e1002079. https://doi.org/10.1371/ journal.ppat.1002079

Zhuang, X., Yang, X., Altieri, A.S., Nelson, D.C., and Pal, U. (2018). Borrelia burgdorferi surface-located Lmp1 protein processed into region-specific polypeptides that are critical for microbial persistence. Cell Microbiol, e12855. https://doi.org/10.1111/cmi.12855 
